Review

\title{
Study of Different Deep Learning Methods for Coronavirus (COVID-19) Pandemic: Taxonomy, Survey and Insights
}

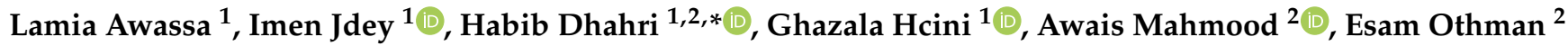 \\ and Muhammad Haneef ${ }^{3}$
}

Citation: Awassa, L.; Jdey, I.; Dhahri, H.; Hcini, G.; Mahmood, A.; Othman, E.; Haneef, M. Study of Different Deep Learning Methods for Coronavirus (COVID-19) Pandemic: Taxonomy, Survey and Insights. Sensors 2022, 22, 1890. https:/ / doi.org/10.3390/s22051890

Academic Editor: Marco Leo

Received: 5 January 2022

Accepted: 21 February 2022

Published: 28 February 2022

Publisher's Note: MDPI stays neutral with regard to jurisdictional claims in published maps and institutional affiliations.

Copyright: (c) 2022 by the authors. Licensee MDPI, Basel, Switzerland. This article is an open access article distributed under the terms and conditions of the Creative Commons Attribution (CC BY) license (https:// creativecommons.org/licenses/by/ $4.0 /)$.
1 Faculty of Sciences and Technology of Sidi Bouzid, University of Kairouan, Kairouan 3100, Tunisia; lamiaawassa2020@gmail.com (L.A.); imen.jdey@fstsbz.u-kairouan.tn (I.J.); hcinighazala@fstsbz.u-kairouan.tn (G.H.)

2 Department of Information Science, College of Applied Computer Sciences, King Saud University, Riyadh 11451, Saudi Arabia; mawais@ksu.edu.sa (A.M.); eothman@ksu.edu.sa (E.O.)

3 Department of Electrical Engineering, Foundation University Islamabad, Islamabad 44000, Pakistan; muhammadhaneef@fui.edu.pk

* Correspondence: hdhahri@ksu.edu.sa

\begin{abstract}
COVID-19 has evolved into one of the most severe and acute illnesses. The number of deaths continues to climb despite the development of vaccines and new strains of the virus have appeared. The early and precise recognition of COVID-19 are key in viably treating patients and containing the pandemic on the whole. Deep learning technology has been shown to be a significant tool in diagnosing COVID-19 and in assisting radiologists to detect anomalies and numerous diseases during this epidemic. This research seeks to provide an overview of novel deep learning-based applications for medical imaging modalities, computer tomography (CT) and chest X-rays (CXR), for the detection and classification COVID-19. First, we give an overview of the taxonomy of medical imaging and present a summary of types of deep learning (DL) methods. Then, utilizing deep learning techniques, we present an overview of systems created for COVID-19 detection and classification. We also give a rundown of the most well-known databases used to train these networks. Finally, we explore the challenges of using deep learning algorithms to detect COVID-19, as well as future research prospects in this field.
\end{abstract}

Keywords: COVID-19; deep learning; diagnostic; computer tomography (CT); chest X-rays (CXR); classification

\section{Introduction}

The Wuhan Municipal Health Commission initially reported a substantial concentration of pneumonia patients in Wuhan City, Hubei Province, China (World Health Organization (WHO), 2020) on 31 December 2019. The virus, known as SARS-CoV-2 (severe acute respiratory syndrome coronavirus 2 ), can cause severe pneumonia and has been shown to spread from person to person [1].

In order to deal with the spread of COVID-19, effective screening and early medical care for affected people are critical requirements. The most commonly utilized clinical screening approach for COVID-19 patients is reverse transcription polymerase chain reaction (RT-PCR), which employs respiratory materials for testing. However, RT-PCR has a poor diagnostic sensitivity, often necessitates multiple tests to confirm infection, and is very time-consuming [2]. To address this problem, an alternative diagnostic approach, based on screening chest radiography images (CRIs), such as X-ray or computed tomography (CT) images, is being developed, as COVID-19 patients frequently exhibit aberrant lung infection characteristics on CRIs [3].

Clinical symptom analyses, epidemiological history, positive radiographic imaging (computed tomography $(\mathrm{CT})$ / chest radiograph $(\mathrm{CXR})$ ), and positive pathogenic tests are among the COVID-19's other diagnostic procedures [4]. 


\subsection{COVID-19}

COVID-19 was declared a global pandemic by the World Health Organization (WHO) in March, 2020 [5]. COVID-19, often known as SARS-CoV-2, is a novel virus in the severe acute respiratory syndrome coronavirus (SARS-CoV) family. Over time, viruses continue to change due to mutations and new virus variants will appear. Sometimes new variants appear and then disappear. Other times, new variations appear and continue to exist. In recent months, several new strains of SARS-CoV-2 have emerged. In the fall of 2020, the United Kingdom (UK) discovered a variant named B.1.1.7 with a substantial number of mutations [6]. Apart from B.1.1.7, another version known as 501Y.V2 or B.1.351 arose in South Africa [7]. B.1.351 and B.1.1.7 have certain mutations in common. In early January, a new strain known as P.1 was discovered in Brazilian travelers who were tested during standard screening at a Japanese airport [8].

In India, a new COVID variant called B.1.617 was first detected in December 2020. B.1.617 is a variation that has had a major impact on the second influx of contaminations in India, and has spread to numerous different nations, including the UK. Between the end of 2020 and the time of writing this paper, several other strains have been identified [9]. SARS-CoV-2 mutations are causing concern all over the world. Indeed, some variants are more contagious and have a higher transmission rate than prior ones [10,11], resulting in an increase of COVID-19 patients. In general, almost all coronavirus variants can be distinguished only by sequencing the genome of the virus. Moreover, despite the discovery of vaccinations against SARS-CoV-2/COVID-19 worldwide, this virus is likely to continue to evolve, which makes controlling it more difficult [12]. The rising number of cases will put more strain on medical services, potentially leading to more hospitalizations and fatalities. It is thus critical to recognize those who are infected. The introduction of automatic detection systems based on AI has shown an encouraging effectiveness of artificial intelligence (AI) in detecting numerous types of malignancies during the large expansion of the COVID-19 outbreak, as these can lead to a quick diagnosis of infected cases and assist in their rapid isolation [13]. Several AI-based solutions have been developed to make COVID-19 detection and decision making in medical image screening faster and more accurate. The use of a deep learning algorithm to perform image classification is an essential element of study disciplines. The implementation of deep learning in the COVID-19 pandemic has resulted in improved disease diagnosis and classification based on both X-ray and CT imaging.

\subsection{Taxonomy of Medical Imaging}

Clinical studies have shown that the majority of COVID-19 patients, during the current coronavirus epidemic, suffer from lung contamination. Early COVID-19 illness detection was achieved using imaging techniques, such as chest $X$-rays (CXR) and computed tomography $(\mathrm{CT})$. Despite the fact that chest $\mathrm{CTs}$ have been shown to be a powerful imaging method for diagnosing lung-related illnesses, chest $X$-rays are more widely available because the diagnostic process is relatively quick [14].

\subsubsection{X-ray Radiography}

X-rays, discovered in 1895 [15], are a sort of electromagnetic radiation. Medical X-rays are used to provide images of internal organs and tissues. These images depict body parts in various shades of black and white. CXR can be used for diagnosing bone fractures, some tumors, and diseases, such as COVID-19 [16]. Specifically, in COVID-19 detection, X-rays are thought to be one of the most effective methods.

\subsubsection{Computed Tomography}

Another medical imaging technique, invented by South African scientist Allan Cormack, is computed tomography (CT), and is sometimes referred to as a CT scan [17]. CT is used in medical diagnosis to slice the imaging of different parts of the body and tissues, such as lungs, bones, veins, etc. Computed tomography plays an important role in the di- 
agnosis of cancer [18], cardiovascular pathologies [19], trauma, and, more recently, COVID pneumonia [20].

\subsection{Paper Structure}

This paper provides a summary of various deep learning algorithms utilized in COVID19 detection and classification using CT and X-ray radiography. The remainder of this review is organized in the following manner: in Section 2, basic and background information of deep learning techniques are presented. Deep learning systems for different image taxonomies are discussed in Section 3. Section 4 presents future directions and challenges. Finally, Section 5 provides the conclusion of this paper.

\section{Basic and Background}

Many studies have proposed different methods for separating COVID-19 pneumonia patients from healthy people. As of late, deep learning, a subset of machine learning [21], has exploded in popularity in the context of medical imaging analysis [22]. COVID-19 detection methods based on deep learning (DL) are being developed using CT and X-ray images [14,23-25]. Thus, DL techniques are regularly utilized to automatically extract features to classify cases infected with COVID-19. Components of these systems are built using a pre-trained model that incorporates transfer learning [26-28], and a few are introduced through personalized networks [29-31].

\subsection{Deep Learning}

Deep learning, a machine learning subfield [32], is based on a network of artificial neurons inspired by the human brain [33]. The network is composed of several layers of neurons; each layer receives and interprets information from the previous layer. Deep learning models have had success in diagnosing system diseases. The convolutional neural network (CNN), recurrent neural network (RNN), deep belief network (DBN), and reinforcement learning are the four most used deep learning architectures (Figure 1).

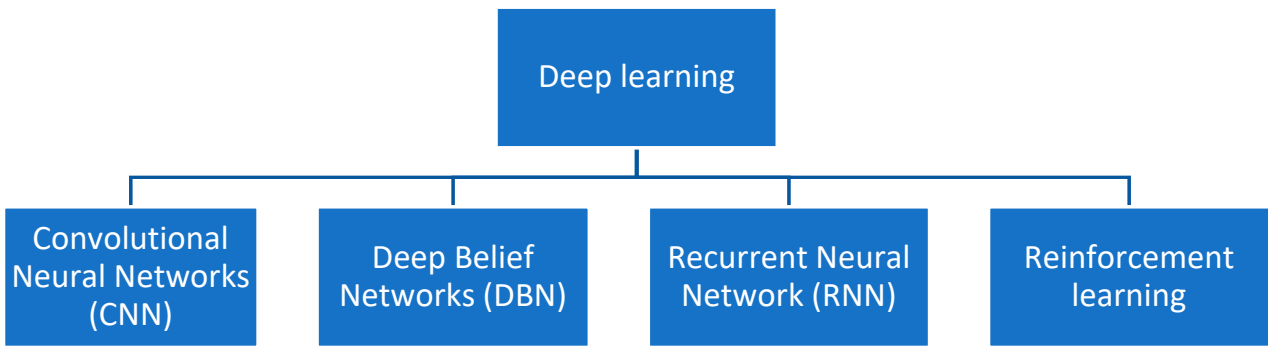

Figure 1. Deep learning-based COVID-19 diagnosis systems.

\subsection{Deep Learning Architectures}

\subsubsection{Convolutional Neural Networks}

Convolutional neural networks $(\mathrm{CNN})$ are a particular type of multilayer perceptron [34], and have demonstrated outstanding performance in computer vision applications, such as image classification. The convolutional neural networks architecture is composed of a convolutional layer, pooling layer, and fully connected layer (see Figure 2). The convolutional layer plays a significant role in the CNN model. Using different types of filters (kernels), convolution extracts different features from an image, such as edges, textures, objects, and greater numbers of filters are used for the convolution process; an activation map is then generated to be fed as the input to the next layer of the CNN [35]. 


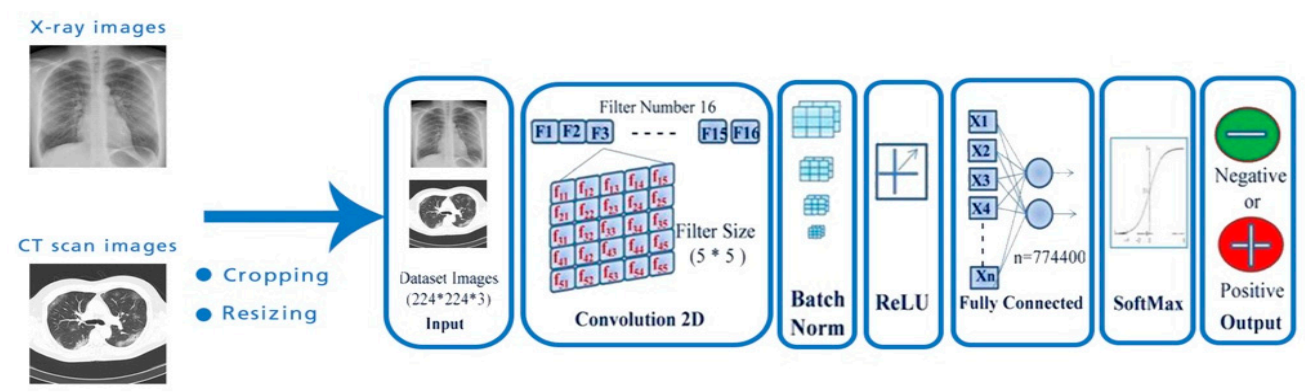

Figure 2. Architecture of a convolutional neural network (CNN) that helps to perform clinical diagnoses using X-ray and CT images.

A pooling layer is incorporated between two convolutional layers and is used to reduce the size of images after they have been convoluted. There are three functions of pooling: max pooling, sum pooling, and average pooling. When applying a fully connected layer after two subsequent convolutional layers, without using average, max, or sum pooling, the calculations and parameter amounts are quite large [36,37].

The fully connected layer is also known as a dense layer and is used to identify an image with a probability value. After flattening, the output of the final pooling or convolutional layer becomes the input for the fully connected layer.

\subsubsection{Recurrent Neural Network}

A sort of neural network known as a recurrent neural network (RNN) is a type of neural network with recurrent connections that uses sequential data or time-series data. It is used for pattern recognition of stream or sequential data, such as speech, handwriting, and text [38].

\subsubsection{Deep Belief Networks}

Deep belief networks (DBNs) are probabilistic generative models with numerous layers of hidden variables. They are an effective method to resolve problems from neural network with deep layers, such as a low velocity and over fitting in learning. A DBN can be considered as the combination of a stack of restricted Boltzmann machines [39]. The layers of the RBMs are connected with previous and subsequent layers. Deep belief networks have two major characteristics: (1) learning top-down, and there is an effective layer-by-layer technique. The generative weights govern how variables in one layer interact with variables in another layer. (2) After learning, a single bottom-up run that starts with an observed data vector in the bottom layer and reverses the generating weights can infer the values of the latent variables in each layer [40].

\subsubsection{Reinforcement Learning}

Reinforcement learning is a type of machine learning that recognizes and solves goaloriented learning and decision-making problems automatically. Reinforcement learning is the set of methods that allows an agent to learn to choose, in an autonomous way, which action to take. It has been used in a variety of industries in recent years, with impressive results [41].

\subsection{Transfer Learning}

Transfer learning is a technique for reusing weights from a model that has been pre-trained on a larger dataset. Only the last few layers of the pre-trained model are replaced and retrained. Transfer learning is the process of leveraging a pre-trained model's expertise to learn a new set of data [22]. This involves training CNNs using a large dataset to extract significant characteristics, and transferring this knowledge to re-train another CNN. There are several pre-trained models utilized in transfer learning, such as ResNet, 
AlexNet, GoogleNet, Visual Geometry Group (VGG), SqueezeNet, Inception, Xception, U-Net, MobileNet, DenseNet, etc.

\subsection{Datasets}

In Table 1, a summary of the publicly available datasets is presented. In deep learning applications, result accuracy depends on high-quality datasets. Several studies have integrated multiple datasets and used them with DL models to achieve enhanced performances in the detection of COVID-19. Both X-ray and CT images were obtained from public repositories, such as Kaggle and GitHub. Generally, two techniques are used for data partitioning: cross validation and splitting data into training, validation, and testing sets. COVID-19-detection systems based on deep learning have been created to serve as an accurate diagnosis for binary and multi classifications. Binary classification is a type of classification with a Boolean outcome (COVID or normal). Multi classification is a kind of classification where the output can be more than two values (COVID, normal, non-COVID viral pneumonia, non-COVID bacterial pneumonia, etc.).

Table 1. Summary of publicly available datasets used in the relevant publications and corresponding URLs (accessed on 17 December 2021).

\begin{tabular}{|c|c|}
\hline Databases & Sources (URL) \\
\hline COVID-19 Image Data Collection & https://github.com/ieee8023/COVID-chestxray-dataset \\
\hline COVID-19 Chest X-ray & https://github.com/agchung/Figure1-COVID-chestxray-dataset \\
\hline ActualMed COVID-19 Chest X-ray dataset & https://github.com/agchung/Actualmed-COVID-chestxray-dataset \\
\hline COVID-19 Radiography Database & https://www.kaggle.com/tawsifurrahman/COVID19-radiography-database \\
\hline RSNA Pneumonia Detection Challenge dataset & https://www.kaggle.com/c/rsna-pneumonia-detection-challenge/data \\
\hline COVID-19 X-ray images & https://www.kaggle.com/bachrr/COVID-chest-xray \\
\hline COVID-19 detection X-ray dataset & https://kaggle.com/darshan1504/COVID19-detection-xray-dataset \\
\hline NIH chest $X$-ray dataset & https://www.kaggle.com/nih-chest-xrays/data \\
\hline COVID-CT & https://github.com/UCSD-AI4H/COVID-CT \\
\hline Chest X-ray images (pneumonia) & https://www.kaggle.com/paultimothymooney/chest-xray-pneumonia/version/1 \\
\hline SARS-CoV-2 CT-scan dataset & https://www.kaggle.com/plameneduardo/sarscov2-ctscan-dataset \\
\hline COVID-19 X-ray dataset (training and testing sets) & https://www.kaggle.com/khoongweihao/COVID19-xray-dataset-train-test-sets \\
\hline COVID-CTset & https://github.com/mr7495/COVID-CTset \\
\hline $\begin{array}{l}\text { Chest X-ray (COVID-19 and pneumonia) } \\
\text { COVID-19 } \\
\text { COVID-19 CT Lung and Infection Segmentation dataset } \\
\text { Labeled COVID-19 CT scans }\end{array}$ & $\begin{array}{c}\text { https://www.kaggle.com/prashant268/chest-xray-COVID19-pneumonia } \\
\text { https://mosmed.ai/en/ } \\
\text { http://medicalsegmentation.com/COVID19/ } \\
\text { https://gitee.com/junma11/COVID-19-CT-Seg-Benchmark }\end{array}$ \\
\hline
\end{tabular}

\subsection{Metrics}

The assessment measures that are used to assess the performance of DL models are outlined in this section. Several benchmark metrics are utilized to evaluate the classification results. A number of metrics, including accuracy, sensitivity, specificity, recall, positive predictive value (PPV), precision, F1 measure (F1), area under the receiver operating characteristic curve (AUC), kappa criteria (Kappa), error, IoU, false positive rate, TNR, NPV, FPR, NPR, LRP, and LRN, are based on a confusion matrix (Table 2).

Table 2. Confusion matrix.

\begin{tabular}{lcc}
\hline & \multicolumn{2}{c}{ Predicted Class } \\
\hline \multirow{2}{*}{ Actual class } & True Positive $($ TP $)$ & False Positive $($ FP) \\
\cline { 2 - 3 } & False Negative $(\mathbf{F N})$ & True Negative $($ TN $)$ \\
\hline
\end{tabular}

Table 3 summarizes a number of metrics used to evaluate the performance of deep learning systems developed for the detection and classification of COVID-19. 
Table 3. Summary of benchmarks metrics used in the relevant publications in this review.

\begin{tabular}{|c|c|}
\hline Metrics & Definition \\
\hline Accuracy & Measure indicates the percentage of correct predictions, Accuracy $=\frac{(\mathrm{TP}+\mathrm{TN})}{(\mathrm{TP}+\mathrm{TN}+\mathrm{FP}+\mathrm{FN})}$. \\
\hline Precision/PPV & Measure indicates the percentage of correct positive predictions, Precision $=\frac{\mathrm{TP}}{(\mathrm{TP}+\mathrm{FP})}$ \\
\hline $\begin{array}{l}\text { Recall } \\
\text { /Sensitivity/TPR }\end{array}$ & $\begin{array}{l}\text { Measure indicates the percentage of positive labeled samples that were predicted as positive, } \\
\qquad \text { Recall }=\frac{\mathrm{TP}}{(\mathrm{TP}+\mathrm{FN})}\end{array}$ \\
\hline F1 score & Measure indicates the harmonic mean of precision and recall, F1 score $=\frac{2 * \text { Precision } * \text { Recall }}{\text { Precision }+ \text { Recall }}$ \\
\hline Specificity/TNR & Measure indicates the percentage of the correct negative predictions, Specificity $=\frac{\mathrm{TN}}{(\mathrm{TN}+\mathrm{FN})}$. \\
\hline AUC & $\begin{array}{l}\text { The area under the curve (AUC) is a total measure of a binary classifier's performance over all } \\
\text { potential threshold settings. }\end{array}$ \\
\hline MCC & $\begin{array}{l}\text { Matthews correlation coefficient shows the true positive rate (TPR) against the false positive } \\
\text { rate (FPR) for various threshold values. } \mathrm{MCC}=\frac{\mathrm{TP} * \mathrm{TN}-\mathrm{FP} * \mathrm{FN}}{(\mathrm{TP}+\mathrm{FP})(\mathrm{TP}+\mathrm{FN})(\mathrm{TN}+\mathrm{FP})(\mathrm{TN}+\mathrm{FN})}\end{array}$ \\
\hline IoU & $\begin{array}{l}\text { Intersection over union (IoU) is an object detection metric that finds the difference between ground } \\
\text { truth annotations and predicted bounding boxes. }\end{array}$ \\
\hline Error & Error is a measure that indicates the percentage of incorrect predictions, Error $=1-$ Accuracy. \\
\hline Kappa & Kappa is an interesting metric used to measure classification performance. \\
\hline ROC AUC/ROC & $\begin{array}{l}\text { The receiver operating characteristic curve is a plot that shows the true positive rate (TPR) against the } \\
\text { false positive rate (FPR) for various threshold values. }\end{array}$ \\
\hline $\begin{array}{l}\text { PR AUC/Average } \\
\text { Precision }\end{array}$ & PR AUC is the average of precision scores calculated for each recall threshold. \\
\hline NPV & $\begin{array}{l}\text { Negative predictive value measures how many predictions out of all negative predictions were } \\
\qquad \text { correct. NPV }=\frac{\mathrm{TN}}{\mathrm{TN}+\mathrm{FN}} .\end{array}$ \\
\hline FPR & False positive rate, $\mathrm{FPR}=\frac{\mathrm{FP}}{(\mathrm{FP}+\mathrm{TN})}$ \\
\hline FNR & False negative rate, $\mathrm{FNR}=\frac{\mathrm{FN}}{\mathrm{TP}+\mathrm{FN}}$ \\
\hline NPR & $\begin{array}{l}\text { False positive rate measures among truly negative cases to determine what percentage of them are } \\
\text { actually false positive. }\end{array}$ \\
\hline LRP & Localization recall precision is an error metric used to evaluate all visual detection tasks. \\
\hline
\end{tabular}

\section{Deep Learning Techniques for Different Image Modalities}

In this paper, we present 50 papers covering COVID-19 classification methods. Twentyone techniques ( $42 \%$ of the total number of reviewed systems) deal with binary classification and 29 (68\% of the total reviewed number of systems) deal with multi-class classification.

Before proceeding with the classification step, the preprocessing phase needs to be underlined. In fact, for AI-based COVID-19 image processing and analysis, segmentation is a crucial stage. It delineates regions of interest (ROIs) in chest X-rays or CT images, such as the lung, lobes, bronchopulmonary segments, and infected regions or lesions, for further assessment and quantification.

We summarize the literature-based information on COVID-19 infection segmentation processes presented in the most recent studies (Table 4). 
Table 4. Summary of deep learning segmentation methods used in the relevant publications in this review.

\begin{tabular}{|c|c|c|c|c|c|c|}
\hline References & Data Set & Modalities & No. of Images & Partitioning & Classifiers & Performances (\%) \\
\hline [42] & $\begin{array}{l}\text { Italian Society } \\
\text { of Medical and } \\
\text { Interventional } \\
\text { Radiology }\end{array}$ & $\mathrm{CT}$ & $\begin{array}{l}1001 \text { lung CT } \\
\text { images }\end{array}$ & $\begin{array}{c}\text { Training }(72 \%) \\
\text { Validation }(10 \%) \\
\text { Testing }(18 \%)\end{array}$ & $\begin{array}{l}\text { SegNet } \\
\text { U-NET }\end{array}$ & $\begin{array}{c}\text { SegNet Sensitivity } \\
0.956 \text { Specificity } \\
0.9542 \\
\text { U-NET } \\
\text { Sensitivity } 0.964 \\
\text { Specificity } 0.948\end{array}$ \\
\hline $\begin{array}{c}\text { (Paluru, N., } \\
\text { Dayal, A., } \\
\text { Jenssen, H.B., } \\
\text { Sakinis, T., } \\
\text { Cenkeramaddi, } \\
\text { L.R., Prakash, J. } \\
\text { and Yalavarthy, } \\
\text { P.K, 2021) [43] }\end{array}$ & $\begin{array}{l}\text { Italian Society } \\
\text { of Medical and } \\
\text { Interventional } \\
\text { Radiology and } \\
\text { Radiopedia }\end{array}$ & $\mathrm{CT}$ & $\begin{array}{l}929 \text { lung CT } \\
\text { images }\end{array}$ & $\begin{array}{l}\text { Training }(70 \%) \\
\text { Testing }(30 \%)\end{array}$ & Anam Net & $\begin{array}{c}\text { Sensitivity } 0.927 \\
\text { Specificity } 0.998 \\
\text { Accuracy } 0.985\end{array}$ \\
\hline $\begin{array}{c}(\text { Yin, 2022) } \\
{[44]}\end{array}$ & $\begin{array}{l}\text { The Italian } \\
\text { Society of } \\
\text { Medical and } \\
\text { Interactive } \\
\text { Radiology }\end{array}$ & $\mathrm{CT}$ & $\begin{array}{l}1963 \text { lung CT } \\
\text { images }\end{array}$ & $\begin{array}{c}\text { Training (1376 CT } \\
\text { images) } \\
\text { Validation (196 } \\
\text { CT images) } \\
\text { Testing (391 CT } \\
\text { images }\end{array}$ & SD-Unet & $\begin{array}{c}\text { Sensitivity } 0.8988 \\
\text { Specificity } 0.9932 \\
\text { Accuracy } 0.9906\end{array}$ \\
\hline $\begin{array}{c}\text { (Shan, et al., 2021) } \\
\text { [45] }\end{array}$ & $\begin{array}{c}\text { Shanghai } \\
\text { Public Health } \\
\text { Clinical Center } \\
\text { and other } \\
\text { centers outside } \\
\text { of Shanghai }\end{array}$ & $\begin{array}{l}\text { CT scan } \\
\text { images }\end{array}$ & 249 images & $\begin{array}{l}\text { Training }(75 \%) \\
\text { Testing }(25 \%)\end{array}$ & $\begin{array}{l}\text { DL-based } \\
\text { segmentation } \\
\text { system } \\
\text { (VB-Net) }\end{array}$ & Accuracy 0.916 \\
\hline [46] & $\begin{array}{l}\text { Integrative } \\
\text { Resource of } \\
\text { Lung CT } \\
\text { Images and } \\
\text { Clinical } \\
\text { Features } \\
\text { (ICTCF) } \\
\text { Med-Seg } \\
\text { (medical } \\
\text { segmentation) } \\
\text { COVID-19 } \\
\text { dataset }\end{array}$ & $\mathrm{CT}$ & $\begin{array}{l}7586 \text { lung CT } \\
\text { images }\end{array}$ & $\begin{array}{c}\text { Training (698 CT } \\
\text { images) } \\
\text { Validation (6654 } \\
\text { CT images) } \\
\text { Testing (117 CT } \\
\text { images) }\end{array}$ & SSInfNet & $\begin{array}{c}\text { F1 score } 0.63 \\
\text { Recall } 0.71 \\
\text { Precision } 0.68\end{array}$ \\
\hline [47] & Private dataset & $\mathrm{CT}$ & 5000 CT images & $\begin{array}{l}\text { Training }(40 \%) \\
\text { Testing }(60 \%)\end{array}$ & $\begin{array}{l}\text { COVLIAS } 1.0 \\
\text { (SegNet, } \\
\text { VGG-SegNet } \\
\text { and ResNet- } \\
\text { SegNet) }\end{array}$ & $\begin{array}{c}\text { AUC: } \\
\text { SegNet } 0.96 \\
\text { VGG-SegNet. } 0.97 \\
\text { ResNet-SegNet } 0.98\end{array}$ \\
\hline [48] & $\begin{array}{l}\text { Multiple } \\
\text { sources of } \\
\text { datasets }\end{array}$ & $\mathrm{CT}$ & 4449 CT images & $\begin{array}{c}\text { Training (4000 CT } \\
\text { images) } \\
\text { Testing (449 CT } \\
\text { images) }\end{array}$ & ResUnet & Dice metric 72.81 \\
\hline
\end{tabular}

For image tissue classification, the authors of [42] proposed using two well-known deep learning networks, SegNet and U-NET. U-NET is a medical segmentation tool, while SegNet is a scene segmentation network. Both networks were used as binary segmentors to distinguish infected from healthy lung tissues, as well as multi-class segmentors to learn the type of infection in the lung. The obtained results demonstrated that SegNet 
outperformed the other approaches in classifying infected/non-infected tissues (with a 0.95 mean accuracy), while U-NET outperformed the others as a multi-class segmentor (with a 0.91 mean accuracy).

Using 929 lung CT images, the authors of [43] proposed a novel segmentation approach named AnamNet. Compared to the state-of-the-art UNet, the proposed Anam-Net had 7.8 times fewer parameters (or variants). The results demonstrated that the suggested method provided good Dice similarity scores for diseased and normal lung regions, with an accuracy of $98 \%$. In [44], the authors designed an encoder-decoder segmentation approach called SD-UNet. The metrics of sensitivity, accuracy, specificity, and similarity were $0.8988,0.8696,0.9906$, and 0.7702 , respectively.

Shan et al. suggested a DL-based segmentation method (VB-Net) for segmenting COVID-19 infection areas in CT scans, which was tested on a dataset of 249 images [45]. It took the form of a 3D convolutional neural network with a bottleneck structure that combines V-Net and a bottleneck structure. VB-Net has two methods to extract global image features: the first approach is to contract a path that includes down-sampling and convolution procedures. The second path is a broad one, which incorporates fine-grained image features through up-sampling and convolution processes.

In [46], it was suggested that a CNN model could be used for COVID-19 lung CT segmentation (SSInfNet). The self-supervised InfNet incorporated various techniques, such as generative adversarial image inpainting, lookahead optimizer, and focal loss. The used dataset consisted of 7586 CT samples, 698 that were used for training, 6654 for validation, and 117 that were used for testing the system. SInfNet achieved an F1 score, recall, and precision of $63 \%, 71 \%$, and $68 \%$ respectively.

COVLIAS 1.0 is a COVID lung image analysis system that was proposed in [47]. The system is composed of three methods SegNet, VGG-SegNet, and ResNet-SegNet. Using a dataset of 5000 lung CT images, COVLIAS 1.0 was benchmarked against the NIH (National Institute of Health) and was founded on a conventional segmentation model using fuzzyconnectedness. The obtained results demonstrated that the three models were better than the conventional NIH model.

Based on the encoder-decoder architecture, a novel segmentation technique was proposed in [48], built on combining multi-scale feature maps of multiple levels. The suggested schemes were validated using four different COVID-19 CT datasets. The results revealed that all three of the proposed modules, the edge supervised module (ESM), semantic supervised module (ASSM), and attention fusion module (AFM) with ResUnet improved the Dice metric by $3.97 \%$.

Segmentors are also considered to be classifiers. As mentioned above, we studied 50 works on deep learning using different images modalities. For each type of classification, the deep learning methods were divided into two categories: pre-trained models with deep transfer learning and personalized deep learning techniques.

\subsection{Binary Classification}

The binary classification is the sort of classification where the output is two classes: COVID-19 or normal, COVID-19 or non-COVID-19, and COVID-19 or pneumonia.

\subsubsection{Pre-Trained Model with Deep Transfer Learning}

In [49], the authors suggested a deep learning architecture for detecting COVID-19 illnesses using X-ray and CT scan pictures of the chest. For diagnoses, the system utilized VGG16, VGG19, Xception, ResNet50V2, MobileNetV2, NasNetMobile, ResNet101V2, and InceptionV3 CNN architectural versions. A total of $1000 \mathrm{X}$-ray and CT scans were used in the investigation, with 805 images from healthy people and the rest from COVID-19 patients. The dataset was divided into two parts, with $80 \%$ of the data used for training and 20\% used for testing. The VGG-19 model had the best accuracy, with a score of $99 \%$.

In [50], two in-depth learning techniques, SegNet and U-NET, were proposed to semantically segment infected tissue regions in CT lung images. Both networks were 
utilized as binary segmentors to distinguish between healthy and infected lung tissues, and multi-class segmentors were used to determine what type of lung infection is present. The experimental findings reveal that SegNet performed comparatively better than the other method in classifying infected/non-infected tissues (with 95\% mean accuracy). U-NET obtained better results as a multi-class segmentor (with 91\% mean accuracy).

In [50], a method based on deep learning networks was introduced to diagnose COVID-19 based on X-ray images using a pre-trained model (ResNet50). The dataset contained $50 \mathrm{X}$-ray images for lungs, where $25 \mathrm{X}$-ray images were for patients with COVID19 and 25 X-ray images were for healthy patients. For the experiment, 5- and 10-fold cross validation used to split the dataset. The model achieved an accuracy of $97.28 \%$ in 5 -fold cross-validation experiments and $95.99 \%$ in 10 -fold cross validation experiments.

In [51], a deep learning-based system for detecting, localizing, and quantifying COVID19 manifestation severity from chest CT scans was suggested. Using 1865 CT images, the model was trained and tested. The system had an AUC of $99.4 \%$, a sensitivity of $94 \%$, and a specificity of $98 \%$, according to the results of the trial.

Table 5 summarizes deep learning models for binary classification of COVID-19 utilizing a pre-trained model and deep transfer learning. Different medical imaging modalities were used in the DL techniques, including computer tomography (CT) and chest X-rays (CXR).

Table 5. COVID-19 binary classification using a deep learning-based pre-trained model and deep transfer learning.

\begin{tabular}{|c|c|c|c|c|c|c|}
\hline Authors & Data Sources & No. of Images & $\begin{array}{l}\text { Name of } \\
\text { Classes }\end{array}$ & Partitioning & Techniques & Performances (\%) \\
\hline$[49]$ & {$[52,53]$} & $\begin{array}{l}1000 \text { chest } X \text {-ray } \\
\text { and CT images } \\
\text { (normal = 805, } \\
\text { COVID-19=195 } \\
\text { (23 lung CT, } 172 \\
\text { chest X-ray) }\end{array}$ & $\begin{array}{l}\text { COVID-19, } \\
\text { Normal }\end{array}$ & $\begin{array}{l}\text { Training }=80 \% \\
\text { Test }=20 \%\end{array}$ & $\begin{array}{c}\text { VGG16, VGG19, } \\
\text { Xception, } \\
\text { ResNet50V2, } \\
\text { MobileNetV2, } \\
\text { NASNetMobile, } \\
\text { ResNet101V2, } \\
\text { and InceptionV3 }\end{array}$ & $\begin{array}{c}\text { Accuracy }=99 \% \\
\text { Sensitivity }=97.4 \% \\
\text { Specificity }=99.4 \%\end{array}$ \\
\hline$[42]$ & {$[54]$} & 100 CT images & $\begin{array}{c}\text { Infected, } \\
\text { non-infected }\end{array}$ & $\begin{array}{c}\text { Training }=70 \% \\
\text { Validation }=10 \% \\
\text { Test }=20 \% \\
\text { 5-fold cross } \\
\text { validation }\end{array}$ & $\begin{array}{l}\text { SegNet, } \\
\text { U-NET }\end{array}$ & $\begin{array}{c}\text { Accuracy }=95 \% \\
\text { Sensitivity }=95.6 \% \\
\text { Specificity }=95.42 \% \\
\text { Dice }=74.9 \% \\
\text { G-mean }=95.5 \% \\
\text { F2 }=86.1 \%\end{array}$ \\
\hline$[50]$ & $\begin{array}{l}\text { X-ray COVID-19 } \\
\text { dataset [55] }\end{array}$ & $\begin{array}{c}50 \text { X-ray images } \\
(\text { COVID }=25 \\
\text { Normal }=25)\end{array}$ & $\begin{array}{l}\text { COVID, } \\
\text { Normal }\end{array}$ & $\begin{array}{c}\text { Training }=80 \% \\
\text { Test }=20 \% \\
5-\text { and } 10 \text {-fold } \\
\text { cross validation. }\end{array}$ & ResNet50 & $\begin{array}{c}\text { 5-folds cross } \\
\text { validation: } \\
\text { Accuracy }=97.28 \% \\
\text { Precision }=96 \% \\
\text { Sensitivity }=96 \% \\
\text { F-measure }=96 \% \\
\text { 10-folds cross } \\
\text { validation: } \\
\text { Accuracy }=95.99 \% \\
\text { Precision }=95.83 \% \\
\text { Sensitivity }=92 \% \\
\text { F-measure }=93.87 \%\end{array}$ \\
\hline$[51]$ & $\begin{array}{c}\text { Development } \\
\text { dataset [56], } \\
\text { Testing dataset: } \\
\text { Zhejiang Province, } \\
\text { China, } \\
\text { lung segmentation } \\
\text { development: } \\
\text { El-Camino Hospital } \\
\text { (CA), } \\
\text { lung segmentation } \\
\text { development: } \\
\text { University Hospitals } \\
\text { of Geneva (HUG). }\end{array}$ & $\begin{array}{c}1865 \text { CT } \\
(\text { normal = 1036, } \\
\text { abnormal = 829) }\end{array}$ & $\begin{array}{l}\text { Normal, } \\
\text { COVID-19 }\end{array}$ & $\begin{array}{c}\text { Training }=1725 \\
\text { Validation }=320 \\
\text { Test }=270\end{array}$ & ResNet-50-2D & $\begin{array}{c}\text { AUC }=99.4 \% \\
\text { Sensitivity }=94 \% \\
\text { Specificity }=98 \%\end{array}$ \\
\hline
\end{tabular}




\subsubsection{Custom Deep Learning Techniques}

In [57], a deep learning model with stochastic pooling for COVID-19 detection was proposed. The system considered $640 \mathrm{CT}$ images from two classes, where 320 samples were COVID-19 cases and 320 were healthy samples. To obtain a better performance, the collected dataset was divided using the 10-fold cross-validation method. The proposed system found a sensitivity of $93.28 \% \pm 1.50 \%$, specificity of $94.00 \% \pm 1.56 \%$, and an accuracy of $93.64 \% \pm 1.42 \%$. In another study, the authors of [58] presented a customdesigned architecture with optimized parameters of variants of a convolutional neural network (CNN). In this work, the system used 753 X-ray images, in which 253 were tagged as COVID-19 and 500 were tagged as normal. Five-fold cross validation was used to test the suggested model. The dataset was split into two sections: training (653 X-ray images) and hold out (653 X-ray images) (100 X-ray). The training set was divided 5-fold, while the hold out part was aimed at testing the model at the end. The experimental results achieved a precision of $99 \%$, recall of $99 \%$, F1 score of $99 \%$, AUC of $99 \%$, and MCC of $99 \%$.

In another research work [59], a diagnosis prototype system based on ResNet50 architecture was proposed. The used COVID-19 CT dataset of the study was obtained from Huangpi Hospital of Traditional Chinese Medicine, Wuhan, China. In this experiment, 1867 CT samples were used for training, 1400 CT samples were used for validation, and 510 samples were used for testing. The experimental results showed that the system obtained an accuracy of $93 \%$, sensitivity of $93 \%$, specificity of $92 \%$, F1 score of $92 \%$, IoU of $85 \%$, and AUC of $93 \%$. In [60], an intelligent decision support system for COVID-19 powered by deep learning (ID2S-COVID19-DL) using X-ray and CT-scan images was presented. The dataset was collected from different sources, such as cameras, $\mathrm{X}$-rays, and CT-scan machines through the Internet of Medical Things (IoMT). The dataset was divided into two sets: training and validation, with each set accounting for $80 \%$ and $20 \%$ of the total, respectively. The created system had a $95.5 \%$ accuracy rate.

Recently, in [61], a new neural network was built for detecting COVID-19 from CXR images that blends topological and deep characteristics (TDA-Net). TDA-Net has two branches: a deep branch that accepts a raw image and a topological branch that accepts a topological feature vector. Both branch outputs are then combined and used to perform a classification. The data were collected from two open-source datasets of chest X-ray and CT images [53-62]. The first dataset consisted of 351 chest X-ray and CT images, which were positive or suspected of COVID-19. The second dataset from Kaggle contained 112,120 X-ray images (287 samples of chest X-ray images of viral and bacterial pneumonia were selected). The data were divided into two parts. The test set comprised $20 \%$ of the overall dataset, with 116 samples being evenly distributed between the positive and negative classes. The suggested that the network had a 93\% accuracy rate.

The authors in [63] introduced a deep learning algorithm based on a modified CNN. In the experiment, a total of $1065 \mathrm{CT}$ images were used for the training set, 455 images were used for the internal validation, and the rest were used for external validation. The external testing dataset achieved a total accuracy of $79.3 \%$. The authors of [64] defined a fully automated system for COVID-19 detection from CT scans. The proposed system made use of the ResNet50V2 model, which is a popular pre-trained model with a feature pyramid network (FPN). In the study, they introduced a new dataset named COVID-CTset. Among the 63,849 images, 15,589 were confirmed COVID-19 cases and 48,260 were normal cases. The scheme used 5-fold cross validation for data partitioning. The system obtained an accuracy of $98.49 \%$. In [65], pre-trained CNN and J48 models were used to construct a system for detecting COVID-19. To extract the features, the algorithm used eleven different architectures of pre-trained models (AlexNet, VGG16, VGG19, GoogleNet, ResNet18, ResNet50, ResNet101, InceptionV3, InceptionResNetV2, DenseNet201, and XceptionNet), as well as J48 for COVID-19 chest X-ray image classification into normal and COVID-19 cases. With accuracy, recall, specificity, precision, and F1 scores of 100 percent, 100 percent, $98.89 \%, 100 \%$, and $100 \%$, respectively, the Resnet101 and J48-based CNN methods were superior for the detection of COVID-19. 
To detect pneumonia, the authors of [66] created the CGNet framework, a novel deep learning model. The dataset was collected from two public datasets. The proposed system achieved an accuracy of $98.72 \%$ on a public pneumonia dataset, which included 5856 chest $X$-ray images. The proposed technique was evaluated on a public COVID-19 CT dataset for the detection of COVID-19 pneumonia. The system achieved an accuracy of $99 \%$, specificity of $100 \%$ and sensitivity of $98 \%$, respectively. In [67], an ensemble of convolutional neural networks was developed to detect COVID-19 and was named DeepCOVID-XR. The proposed algorithm was trained and validated on 13,156 CXR images and then tested on 1879 CXR images. For the entire test, DeepCOVID-XR obtained an accuracy of $83 \%$, and an AUC of $90 \%$. For 300 random test images, the system achieved an accuracy of $82 \%$. The authors of [68] described a powerful deep learning strategy for detecting coronavirus infection. Convolutional neural networks (CNN) and convolutional long short-term memory (CLSM) were used in the suggested system (ConvLSTM). The network was tested on both CT and X-ray images, and on a combined dataset (X-ray and CT). To achieve a better result, the dataset was divided into $70 \%$ training and $30 \%$ testing sets. In other circumstances, the proposed CNN modality obtained a $100 \%$ accuracy and a 100\% F1 score.

The authors of Saha [69] advocated using X-ray images to identify COVID-19 patients using an automated detection system called EMCNet. EMCNet uses CNN to extract features from images and an ensemble of four different ML classifiers to classify COVID-19 (random forest, support vector machine, decision tree, and AdaBoost). The dataset was divided into three parts: training, validation, and testing. The training, validation, and testing sets each received $70 \%, 20 \%$, and 10\% of the total set of images. EMCNet obtained accuracy, precision, recall, and F1 score of $98.91 \%, 100 \%, 97.82 \%$, and $98.89 \%$, respectively.

In [70], pre-trained CNN models were used to construct an autonomous approach for diagnosing coronavirus from CT images. The proposed system combined two variants of CNNs (ResNet5 and ResNet-101). ResNet50 was utilized to distinguish virally induced pneumonia from bacterially induced pneumonia and normal cases in this investigation, while ResNet-101 was used to detect the presence of COVID-19 in positive viral-induced pneumonia patients using $X$-ray images. The data were collected from two open-source image databases, Cohen and Kaggle. Among the 1365 chest X-ray images, 250 were confirmed as COVID-19. To obtain better performance, two evaluations were used: trainingvalidation-testing and 5-fold cross validation procedures. The developed system obtained a high classification accuracy of $97.77 \%$. Further, the proposed model achieved an averaged accuracy with 5-fold cross validation.

In [71], the authors described a COVID MTNet system for COVID-19 identification and contaminated region localization using two medical imaging modalities (X-ray and CT images). The inception recurrent residual neural network (IRRCNN) and NABLA-3 network models were used in the study for the classification and segmentation tasks. There were a total of 5216 samples, with only 1341 samples for normal cases and 3875 samples for pneumonia. The created system had an X-ray image testing accuracy of $84.67 \%$ and a CT image testing accuracy of $98.78 \%$. In a different project [72], 3D CT volumes were used to construct a weakly-supervised deep learning-based software solution to detect COVID-19 (DeCoVNet). A pre-trained UNet was used to segment the lung region, and the segmented 3D lung region was then fed into a 3D deep neural network to predict the likelihood of COVID-19 being infectious. The data were split into two parts: training (499 CT volumes) and testing (499 CT volumes) (131 CT volumes). The proposed system had a ROC AUC of $95.9 \%$ and a PR AUC of $97.6 \%$, respectively.

In [73], a system for diagnosing coronavirus from CT images was suggested, based on a deep learning algorithm called CTnet-10, which is a variation of CNN. This study used 738 CT scan pictures, 349 of which were obtained from COVID-19-infected patients and 463 were from non-COVID-19-infected patients. The data were divided into three sets: training, validation, and test, in a ratio of 80:10:10. The designed system achieved an accuracy of $82.1 \%$ in the test case. 
Table 6 presents a summary of the deep learning models used for binary classification of COVID-19 using custom deep learning techniques. The DL methods employed different medical imaging modalities: computer tomography (CT) and chest X-rays (CXR).

Table 6. Summary of deep learning based COVID-19 binary classification using custom models.

\begin{tabular}{|c|c|c|c|c|c|c|}
\hline Authors & Data Sources & No. of Images & $\begin{array}{l}\text { Name of } \\
\text { Classes }\end{array}$ & Partitioning & Techniques & Performances (\%) \\
\hline$[57]$ & Local hospitals & $\begin{array}{c}640 \text { CT (COVID-19 } \\
=320, \text { healthy } \\
\text { controls }(\mathrm{HCs}) \\
=320\end{array}$ & $\begin{array}{l}\text { COVID-19, } \\
\text { HC }\end{array}$ & $\begin{array}{l}10 \text {-fold cross } \\
\text { validation }\end{array}$ & 5LDCNN-SP-C & $\begin{array}{c}\text { Sensitivity }=93.28 \% \\
\pm 1.50 \% \\
\text { Specificity }=94.00 \% \\
\pm 1.56 \% \\
\text { Accuracy }=93.64 \% \\
\pm 1.42 \%\end{array}$ \\
\hline$[58]$ & $\begin{array}{l}\text { data collection from } \\
\text { Mendeley [52], } \\
\text { The Cancer Imaging } \\
\text { Archive (TCIA) [74], } \\
\text { collection of X-rays } \\
\text { and CT images that } \\
\text { are COVID-19 } \\
\text { positive [75] }\end{array}$ & $\begin{array}{c}753 \text { X-ray images } \\
(\text { COVID-19 = 253 } \\
\text { normal }=500)\end{array}$ & $\begin{array}{l}\text { COVID-19, } \\
\text { Normal }\end{array}$ & $\begin{array}{c}\text { Train = 653: } \\
\text { 5-fold cross } \\
\text { validation } \\
\text { Hold out }=100\end{array}$ & CNN & $\begin{array}{c}\text { Hold out test: } \\
\text { Precision }=99 \% \\
\text { Recall }=99 \% \\
\text { F1 score }=99 \% \\
\text { AUC }=99 \% \\
\text { MCC }=99 \%\end{array}$ \\
\hline$[59]$ & $\begin{array}{c}\text { COVID-ct- } \\
\text { dataset [76], } \\
\text { Guangxi Medical } \\
\text { University hospitals }\end{array}$ & $\begin{array}{l}2592 \text { CT images } \\
\text { (COVID-19 = 1357, } \\
\text { non-infected } \\
=1235)\end{array}$ & $\begin{array}{l}\text { COVID-19, } \\
\text { non-infected }\end{array}$ & $\begin{array}{c}\text { Training }=1867 \\
\text { Validation }=1400 \\
\text { Test }=510\end{array}$ & $\begin{array}{l}\text { Modified } \\
\text { ResNet50 }\end{array}$ & $\begin{array}{c}\text { Specificity }=92 \% \\
\text { Sensitivity }=93 \% \\
\text { Accuracy }=93 \% \\
\text { IoU }=0.85 \\
\text { F1 score }=92 \% \\
\text { AUC }=93 \%\end{array}$ \\
\hline$[60]$ & IOT & & $\begin{array}{c}\text { COVID, } \\
\text { non-COVID }\end{array}$ & $\begin{array}{c}\text { Training }=70 \% \\
\text { Validation }=30 \%\end{array}$ & $\begin{array}{l}\text { ID2S-COVID19- } \\
\text { DL }\end{array}$ & $\begin{array}{c}\text { Accuracy }=95.5 \% \\
\text { Sensitivity }=94.38 \% \\
\text { Specificity }=97.06 \% \\
\text { Miss rate }=1.89 \% \\
\text { PPV }=98.51 \% \\
\text { NPV }=97.62 \% \\
\text { FPR }=54.46 \% \\
\text { NPR }=0.02 \% \\
\text { LRP }=97.61 \% \\
\text { LRN }=98.51 \%\end{array}$ \\
\hline$[61]$ & $\begin{array}{c}\text { Open-source } \\
\text { dataset [53], } \\
\text { dataset from } \\
\text { Kaggle [62] }\end{array}$ & $\begin{array}{c}574 \text { CXR images } \\
\text { (COVID = 287, } \\
\text { viral and bacterial } \\
\text { pneumonia = 287) }\end{array}$ & $\begin{array}{c}\text { COVID, } \\
\text { non-COVID }\end{array}$ & $\begin{array}{c}\text { Training }=80 \% \\
\text { leave-Out }=20 \%\end{array}$ & TDA-Net & $\begin{array}{c}\text { Accuracy }=93 \% \\
\text { Precision }=88 \% \\
\text { Recall }=95 \% \\
\text { F1 score }=92 \% \\
\text { AUC }=100 \% \\
\text { TNR }=91 \%\end{array}$ \\
\hline$[63]$ & $\begin{array}{c}\text { Dataset collected } \\
\text { from } 3 \text { centers: } \\
\text { Xi'an Jiaotong } \\
\text { University First } \\
\text { Affiliated Hospital } \\
\text { (center 1), } \\
\text { Nanchang } \\
\text { University First } \\
\text { Hospital (center 2), } \\
\text { Xi'an No.8 Hospital } \\
\text { of Xi'an Medical } \\
\text { College (center 3) }\end{array}$ & $\begin{array}{c}1065 \text { CT images } \\
\text { (COVID-19, typical } \\
\text { pneumonia) }\end{array}$ & $\begin{array}{l}\text { COVID-19, } \\
\text { typical } \\
\text { pneumonia }\end{array}$ & $\begin{array}{c}\text { Training }=320 \\
\text { Internal Validation } \\
=455 \\
\begin{array}{c}\text { External validation } \\
=290 .\end{array}\end{array}$ & $\begin{array}{l}\text { Modified } \\
\text { Inception }\end{array}$ & $\begin{array}{l}\text { Accuracy }=79.3 \% \\
\text { Specificity }=83 \% \\
\text { Sensitivity }=67 \%\end{array}$ \\
\hline$[64]$ & COVID-CTset [77] & $\begin{array}{c}63,849 \text { CT scan } \\
\text { images (normal } \\
=48,260 \\
\text { COVID-19 } \\
=15,589)\end{array}$ & $\begin{array}{l}\text { COVID-19, } \\
\text { normal }\end{array}$ & $\begin{array}{l}5 \text {-fold cross } \\
\text { validation }\end{array}$ & $\begin{array}{c}\text { ResNet50V2 + } \\
\text { FPN }\end{array}$ & Accuracy $=98.49 \%$ \\
\hline
\end{tabular}


Table 6. Cont.

\begin{tabular}{|c|c|c|c|c|c|c|}
\hline Authors & Data Sources & No. of Images & $\begin{array}{l}\text { Name of } \\
\text { Classes }\end{array}$ & Partitioning & Techniques & Performances (\%) \\
\hline$[65]$ & $\begin{array}{c}\text { Open source } \\
\text { repository provided } \\
\text { by }[53,78]\end{array}$ & $\begin{array}{c}100 \text { patients }(50 \\
\text { COVID-19, } \\
50 \text { normal) }\end{array}$ & $\begin{array}{c}\text { COVID-19, } \\
\text { normal }\end{array}$ & $\begin{array}{c}\mathrm{k} \text {-fold cross } \\
\text { validation }(\mathrm{k}=5 \\
\text { and } \mathrm{k}=10 \text {-fold })\end{array}$ & ResNet101 + J48 & $\begin{array}{c}\mathrm{k}=5 \text {-fold cross } \\
\text { validation: } \\
\text { Accuracy }=97.18 \% \\
\text { Recall }=98.64 \% \\
\text { Specificity }=95.86 \% \\
\text { Precision }=98.64 \% \\
\text { F1 score }=97.05 \% \\
\text { k }=10-\text { fold cross } \\
\text { validation: } \\
\text { Accuracy }=100 \% \\
\text { Recall }=100 \% \\
\text { Specificity }=98.89 \% \\
\text { Precision }=100 \% \\
\text { F1 score }=100 \%\end{array}$ \\
\hline$[66]$ & $\begin{array}{c}\text { public COVID-19 CT } \\
\text { dataset [76], } \\
\text { Public pneumonia } \\
\text { dataset [78], }\end{array}$ & $\begin{array}{c}\text { public pneumonia } \\
\text { dataset: } \\
5856 \text { X-ray images } \\
\text { (normal and } \\
\text { pneumonia) } \\
\text { public COVID-19 } \\
\text { CT dataset: } \\
746 \text { CT images } \\
\text { (normal and } \\
\text { pneumonia) }\end{array}$ & $\begin{array}{c}\text { Pneumonia, } \\
\text { normal }\end{array}$ & $\begin{array}{c}\text { Public pneumonia } \\
\text { dataset: } \\
\text { Training }=5216 \\
\text { Validation }=16 \\
\text { Testing }=624 \\
\text { public pneumonia } \\
\text { dataset: } \\
\text { Training }=425 \\
\text { Validation }=118 \\
\text { Testing }=203\end{array}$ & CGNet & $\begin{array}{c}\text { Public pneumonia } \\
\text { dataset: } \\
\text { Accuracy }=98.72 \% \\
\text { Sensitivity }=100 \% \\
\text { Specificity = 97.95\% } \\
\text { Public COVID-19 CT } \\
\text { dataset: } \\
\text { Accuracy }=99 \% \\
\text { Sensitivity }=100 \% \\
\text { Specificity }=98 \%\end{array}$ \\
\hline$[67]$ & $\begin{array}{c}\text { Sites the } \\
\text { Northwestern } \\
\text { Memorial Health } \\
\text { Care System }\end{array}$ & $\begin{array}{c}\text { 15,035 CXR images } \\
(\text { COVID-19 } \\
\text { positive }=4750 \\
\text { COVID-19 } \\
\text { Negative }=10,285)\end{array}$ & $\begin{array}{l}\text { COVID- } \\
\text { positive, } \\
\text { COVID- } \\
\text { negative }\end{array}$ & $\begin{array}{c}\text { Training }=10,470 \\
\text { validation }=2686 \\
\text { Testing }=1879\end{array}$ & DeepCOVID-XR & $\begin{array}{c}\text { For the entire test set: } \\
\text { Accuracy }=83 \% \\
\text { AUC }=90 \% \\
\text { For } 300 \text { random test } \\
\text { images: } \\
\text { Accuracy }=82 \%\end{array}$ \\
\hline
\end{tabular}

\begin{tabular}{|c|c|c|c|c|c|c|}
\hline [68] & $\begin{array}{c}\text { Dataset includes CT } \\
\text { images [79], } \\
\text { dataset includes } \\
\text { X-ray images [80], } \\
\text { COVID-19 } \\
\text { radiography } \\
\text { dataset [81] }\end{array}$ & $\begin{array}{c}6130 \text { images } \\
(\text { COVID-19= } 3065 \\
\text { non-COVID-19 } \\
=3065)\end{array}$ & $\begin{array}{l}\text { COVID-19, } \\
\text { viral } \\
\text { pneumonia }\end{array}$ & $\begin{array}{l}\text { Training }=70 \% \\
\text { Test }=30 \%\end{array}$ & $\begin{array}{c}\text { CNN + } \\
\text { ConvLSTM }\end{array}$ & Accuracy $=100 \%$ \\
\hline [69] & $\begin{array}{c}\text { Multiple } \\
\text { sources }[53,54,62,80,82]\end{array}$ & $\begin{array}{c}4600 \text { X-ray images } \\
(\text { COVID-19 = 2300, } \\
\text { Normal = 2300) }\end{array}$ & $\begin{array}{l}\text { COVID-19, } \\
\text { normal }\end{array}$ & $\begin{array}{c}\text { Training }=70 \% \\
\text { Validation }=20 \% \\
\text { Test }=10 \%\end{array}$ & EMCNet & $\begin{array}{c}\text { Accuracy }=98.91 \% \\
\text { Precision }=100 \% \\
\text { Recall }=97.82 \% \\
\text { F1 score }=98.89 \%\end{array}$ \\
\hline [70] & $\begin{array}{c}\text { Two open-source } \\
\text { image } \\
\text { databases }[53,78]\end{array}$ & $\begin{array}{c}1365 \text { chest X-ray } \\
\text { images } \\
(\text { COVID-19 = 250, } \\
\text { normal = 315, Viral } \\
\text { Pneumonia = 350, } \\
\text { bacterial } \\
\text { pneumonia = 300, } \\
\text { Other }=150)\end{array}$ & $\begin{array}{l}\text { COVID-19, } \\
\text { other }\end{array}$ & $\begin{array}{c}\text { Training }=70 \% \\
\text { Validation }=20 \% \\
\text { Test }=10 \% \\
\text { 5-fold cross } \\
\text { validation }\end{array}$ & $\begin{array}{l}\text { ResNet50 + } \\
\text { ResNet-101 }\end{array}$ & $\begin{array}{c}\text { Accuracy }=97.77 \% \\
\text { Recall }=97.14 \% \\
\text { Precision }=97.14 \% \\
\text { With cCross } \\
\text { validation: } \\
\text { Accuracy }=98.93 \% \\
\text { Sensitivity }=98.93 \% \\
\text { Specificity }=98.66 \% \\
\text { Precision }=96.39 \% \\
\text { F1 score }=98.15 \%\end{array}$ \\
\hline [71] & $\begin{array}{c}\text { Joseph Paul Cohen } \\
\text { dataset [53], Publicly } \\
\text { available } \\
\text { dataset [78], }\end{array}$ & $\begin{array}{c}5216 \text { chest } X \text {-ray } \\
\text { and CT images } \\
\text { (normal = 1341, } \\
\text { pneumonia }=3875 \text { ) }\end{array}$ & $\begin{array}{l}\text { COVID-19, } \\
\text { normal }\end{array}$ & $\begin{array}{l}\text { Training }=80 \% \\
\text { Test }=20 \%\end{array}$ & IRRCNN & $\begin{array}{c}\text { X-ray images: } \\
\text { Accuracy = 84.67\% } \\
\text { CT images: } \\
\text { Accuracy }=98.78 \%\end{array}$ \\
\hline$[72]$ & $\begin{array}{c}\text { Archiving and } \\
\text { communication } \\
\text { system (PACS) of the } \\
\text { radiology } \\
\text { department (Union } \\
\text { Hospital, Tongji } \\
\text { Medical College, } \\
\text { Huazhong } \\
\text { University of Science } \\
\text { and Tech) }\end{array}$ & $\begin{array}{l}540 \text { CT images } \\
\text { (COVID- } \\
\text { positive = 313, } \\
\text { COVID- } \\
\text { negative }=229)\end{array}$ & $\begin{array}{l}\text { COVID- } \\
\text { positive, } \\
\text { COVID- } \\
\text { negative }\end{array}$ & $\begin{array}{l}\text { Training }=499 \\
\quad \text { Test }=131\end{array}$ & DeCoVNet & $\begin{array}{c}\text { ROC AUC }=95.9 \% \\
\text { PR AUC }=97.6 \% \\
\text { Sensitivity }=90.7 \% \\
\text { Specificity }=91.1 \%\end{array}$ \\
\hline$[73]$ & $\begin{array}{l}\text { COVID-19 CT } \\
\text { dataset [76] }\end{array}$ & $\begin{array}{c}738 \text { CT images } \\
(\text { COVID }=349 \\
\text { non-COVID }=463)\end{array}$ & $\begin{array}{l}\text { COVID, } \\
\text { non COVID }\end{array}$ & $\begin{array}{c}\text { Training }=80 \% \\
\text { Validation }=10 \% \\
\text { Test }=10 \%\end{array}$ & CTnet-10 & Accuracy $=82.1 \%$ \\
\hline
\end{tabular}




\subsection{Multi-Classification}

\subsubsection{Pre-Trained Model with Deep Transfer Learning}

The authors of [83] developed a COVID-19 detection framework that used the notion of a pre-trained model to automatically classify positive COVID-19 chest X-rays and CT scans into three severity classes: normal, mild/moderate, and severe. The suggested approach combined transfer learning with three prominent pre-trained CNN models: AlexNet, GoogleNet, and Resnet50. The system considered 1491 chest X-rays and CT scans, including 1335 normal, 106 mild/moderate, and 50 severe cases for experiments. The dataset was divided into three parts, $70 \%$ for training, $15 \%$ for validation and $15 \%$ for testing. ResNet50 outperformed the other models used and obtained an overall accuracy of $87.8 \%$.

The authors of [84] suggested a three-label classification framework with an ensemble of convolutional neural network (DenseNet161) models concentrating on both global and local pathological variables from CXR lung images to detect COVID-19. In this system, 11,197 CXR images were considered, 1056 samples were COVID-19, 5451 were pneumonia, 931 were viral pneumonia, and 7217 were control (normal and other pulmonary diseases). The split of the dataset was $70 \%, 15 \%$, and $15 \%$ for training, validation, and testing, respectively. In a multi-label classification framework that included COVID-19, pneumonia, and control classes, the suggested system achieved an average balanced accuracy of $91.2 \%$, average precision of $92.4 \%$, and F1 score of $91.9 \%$.

In another research project [85], DenseNet-121 was used to construct a deep learningbased strategy for detecting COVID-19 patients. The suggested system was trained and tested using the COVIDx dataset, which included 13,800 chest radiography pictures from 13,725 patients. To get a better result, the obtained dataset was divided using the 10 -fold cross-validation approach. The model was put to the test for two-class classification (COVID-19 and non-COVID-19) and three-class classification (COVID-19 and non-COVID-19) (COVID-19, pneumonia, and normal). The proposed network achieved a $96.49 \%$ accuracy for the two-class classification and $93.71 \%$ accuracy for the threeclass classification. In [86], a framework of cascaded deep learning classifiers for automated diagnosis of COVID-19 and pneumonia diseases using chest $\mathrm{X}$-rays was proposed. VGG16, VGG19, Xception, dense convolutional network (DenseNet-121), DenseNet169, DenseNet201, residual neural network (ResNet-50V2), ResNet101V2, ResNet169V2, MobileNet, and MobileNetV2 are some of the deep learning models used in this architecture. VGG16, ResNet50V2, and dense neural network (DenseNet169) were the top fine-tuning models in terms of detection accuracy (99.9 percent). For identifying COVID-19 chest X-ray images, the authors of [87] used a light-weight convolutional network architecture with three backbones (VGG-16, ResNet50, and EfficientNetB0). In this research, the dataset was collected from two available chest $\mathrm{X}$-ray datasets. The datasets maintained a ratio of $80 \%$ and $20 \%$ for training and testing sets, respectively. The proposed models achieved an overall accuracy of $90 \%, 94.3 \%$, and $96.8 \%$ for VGG16, ResNet50, and EfficientNetB0 backbones, respectively.

In [88], CXR images were used to build a technique for detecting COVID-19 pneumonia, non-COVID-19 viral pneumonia, bacterial pneumonia, and healthy patients. AlexNet was the pre-trained model in this system. The datasets were separated into two categories: $70 \%$ for training and 30\% for testing. The network was trained to perform two-way classification, three-way classification, and four-way classification (COVID-19 vs. normal, bacterial pneumonia vs. normal, non-COVID-19 viral pneumonia vs. normal, and COVID-19 vs. bacterial pneumonia). The model achieved a $99.62 \%$ testing accuracy, $90.63 \%$ sensitivity, and $99.89 \%$ specificity for the classification of COVID-19 pneumonia and non-COVID-19 viral pneumonia.

In [89], a COVID-19 detection model based on Inception V3, Xception, and ResNeXt architectures was suggested. A total of 6432 CXR scan samples were acquired from a Kaggle library for the research. A total of 5467 samples were utilized for training, while 965 samples were used for validation. In comparison to other models, the Xception model 
fared better. For detecting chest X-ray pictures, Xception had an overall accuracy of $97.97 \%$. The authors [90], also described a method that uses transfer learning and model integration to detect COVID-19. The information was gathered from two different datasets: the RSNA pneumonia dataset and the chest $X$-Ray dataset. The dataset was split into two sections: training (16,714 X-ray images) and testing (16,714 X-ray images) (1862 X-ray). On the testing set, the suggested model correctly identified $96.1 \%$ of the types of chest X-ray images.

In [91], a method for detecting coronavirus illness based on deep transfer learning and several pre-trained models was proposed. VGG16, VGG19, DenseNet201, Inception ResNet V2, Inception V3, Resnet50, and MobileNet V2 are the seven most common pretrained models. For the experiments, 6087 chest $X$-ray images and CT images were used (2780 images of bacterial pneumonia, 1493 images of coronavirus, 231 images of COVID-19, and 1583 normal images). In this system, the training and validation data partitions were kept at an 80:20 ratio. Densnet201 and Inception Resnet V2 performed better than the other models employed in the study $(92.18 \%$ accuracy for Inception-ResNetV2 and 88.09\% accuracy for Densnet201).

Table 7 summarizes the deep learning models for multi-class classification utilizing a pre-trained model with deep transfer learning for the COVID-19 dataset. Different medical imaging modalities were used in the DL techniques (computer tomography (CT) and chest X-rays (CXR)).

Table 7. Summary of deep learning based COVID-19 multi-classification using pre-trained model with deep transfer learning.

\begin{tabular}{|c|c|c|c|c|c|c|}
\hline Authors & Data Sources & No. of Images & $\begin{array}{l}\text { Name of } \\
\text { Classes }\end{array}$ & Partitioning & Techniques & Performances (\%) \\
\hline [83] & $\begin{array}{l}\text { Two Kaggle } \\
\text { datasets }[4,92], \\
\text { COVID-19 } \\
\text { image data } \\
\text { collection [53] }\end{array}$ & $\begin{array}{l}1491 \text { chest } X \text {-rays } \\
\text { and CT scans } \\
(\text { normal = 1335, } \\
\text { mild } / \text { moderate } \\
=106, \text { severe }=50 \text { ) }\end{array}$ & $\begin{array}{l}\text { Normal, } \\
\text { mild/moderate, } \\
\text { Severe }\end{array}$ & $\begin{array}{c}\text { Training }=70 \% \\
\text { Validation } \\
=15 \% \text { Test } \\
=15 \%\end{array}$ & $\begin{array}{l}\text { AlexNet } \\
\text { GoogleNet } \\
\text { Resnet50 }\end{array}$ & $\begin{array}{c}\begin{array}{c}\text { Average accuracy } \\
\text { (non-augmented) }\end{array} \\
\text { AlexNet } 81.48 \% \\
\text { GoogleNet } 78.71 \% \\
\text { Resnet50 82.10\% } \\
\text { Average accuracy } \\
\text { (augmented) } \\
\text { AlexNet } 83.70 \% \\
\text { GoogleNet } 81.60 \% \\
\text { Resnet50 } 87.80 \%\end{array}$ \\
\hline [84] & $\begin{array}{c}\text { BIMCV } \\
\text { COVID-19 } \\
\text { dataset [93], } \\
\text { PadChest } \\
\text { dataset [94] }\end{array}$ & $\begin{array}{c}\text { 11,197 CXR } \\
(\text { Control = 7217, } \\
\text { pneumonia = 5451, } \\
\text { COVID-19 = 1056) }\end{array}$ & $\begin{array}{l}\text { Control, } \\
\text { pneumonia, } \\
\text { COVID-19 }\end{array}$ & $\begin{array}{c}\text { Training }=70 \% \\
\text { Validation } \\
=15 \% \\
\text { Test }=15 \%\end{array}$ & DenseNet161 & $\begin{array}{l}\text { Average balanced } \\
\text { accuracy }=91.2 \% \text {, } \\
\text { Average precision } \\
\quad=92.4 \% \\
\text { F1 score }=91.9 \%\end{array}$ \\
\hline [85] & $\begin{array}{c}\text { COVIDx } \\
\text { dataset [95] }\end{array}$ & $\begin{array}{l}\text { 15,177 Chest X-ray } \\
\text { images (COVID-19 } \\
=238, \text { pneumonia } \\
=6045, \text { Normal } \\
=8851)\end{array}$ & $\begin{array}{l}\text { COVID-19, } \\
\text { non-COVID- } \\
\text { COVID-19, } \\
\text { pneumonia, } \\
\text { normal }\end{array}$ & $\begin{array}{c}\text { Training }=80 \% \\
\text { Validation } \\
=10 \% \\
\text { Test }=10 \% \\
10-\text { fold cross } \\
\text { validation }\end{array}$ & DenseNet-121 & $\begin{array}{c}\text { Two-class: } \\
\text { Accuracy }=96 \% \\
\text { Precision }=96 \% \\
\text { Recall }=96 \% \\
\text { F-score }=96 \% \\
\text { Three-class: } \\
\text { Accuracy }=93 \% \\
\text { Precision }=92 \% \\
\text { Recall }=92 \% \\
\text { F-score }=92 \%\end{array}$ \\
\hline
\end{tabular}


Table 7. Cont.

\begin{tabular}{|c|c|c|c|c|c|c|}
\hline Authors & Data Sources & No. of Images & $\begin{array}{l}\text { Name of } \\
\text { Classes }\end{array}$ & Partitioning & Techniques & Performances (\%) \\
\hline [86] & $\begin{array}{l}\text { Public dataset } \\
\text { of X-ray } \\
\text { images } \\
\text { collected } \\
\text { by [53] }\end{array}$ & $\begin{array}{l}306 \text { X-ray images } \\
(\text { normal }=79, \\
\text { COVID-19 = 69, } \\
\text { viral pneumonia } \\
=79, \text { bacterial } \\
\text { pneumonia }=79 \text { ) }\end{array}$ & $\begin{array}{l}\text { Normal, } \\
\text { COVID-19, } \\
\text { viral } \\
\text { pneumonia, } \\
\text { bacterial } \\
\text { pneumonia }\end{array}$ & $\begin{array}{l}\text { Training }=85 \% \\
\text { Test }=15 \%\end{array}$ & $\begin{array}{c}\text { Cascaded deep } \\
\text { learning } \\
\text { classifiers } \\
\text { (VGG16, } \\
\text { ResNet50V2, } \\
\text { DenseNet169) }\end{array}$ & Accuracy $=99.9 \%$ \\
\hline [87] & {$[53,78]$} & $\begin{array}{c}673 \text { X-ray and CT } \\
\text { images }(\text { COVID-19 } \\
=202, \text { normal }=300, \\
\text { pneumonia }=300)\end{array}$ & $\begin{array}{l}\text { COVID-19, } \\
\text { pneumonia, } \\
\text { normal }\end{array}$ & $\begin{array}{l}\text { Training }=80 \% \\
\text { Test }=20 \%\end{array}$ & $\begin{array}{c}\text { VGG-16, } \\
\text { ResNet50, } \\
\text { EfficientNetB0 }\end{array}$ & Accuracy $=96.8 \%$ \\
\hline [88] & $\begin{array}{c}\text { Multiple } \\
\text { sources } \\
{[52,53,81,96]}\end{array}$ & $\begin{array}{c}\text { 11568 X-ray images } \\
\text { (COVID-19 = 371, } \\
\text { non-COVID-19 } \\
\text { viral pneumonia } \\
=4237, \text { bacterial } \\
\text { pneumonia }=4078, \\
\text { normal }=2882)\end{array}$ & $\begin{array}{l}\text { COVID-19, } \\
\text { viral } \\
\text { pneumonia, } \\
\text { bacterial } \\
\text { pneumonia, } \\
\text { normal }\end{array}$ & $\begin{array}{l}\text { Training }=70 \% \\
\text { Test }=30 \%\end{array}$ & AlexNet & $\begin{array}{l}\text { Accuracy }=99.62 \% \\
\text { Sensitivity }=90.63 \% \\
\text { Specificity }=99.89 \%\end{array}$ \\
\hline [89] & $\begin{array}{l}\text { Kaggle reposi- } \\
\text { tory [97] }\end{array}$ & $\begin{array}{l}6432(\text { COVID-19 } \\
=576, \text { pneumonia } \\
=4273, \text { normal } \\
=1583)\end{array}$ & $\begin{array}{l}\text { COVID-19, } \\
\text { pneumonia, } \\
\text { normal }\end{array}$ & $\begin{array}{l}\text { Training }=5467 \\
\text { Validation }=965\end{array}$ & $\begin{array}{l}\text { CNN models: } \\
\text { Inception V3 } \\
\text { Xception } \\
\text { ResNeXt }\end{array}$ & Accuracy $=97.97 \%$ \\
\hline [90] & $\begin{array}{l}\text { chest X-ray } \\
\text { dataset [53], } \\
\text { RSNA } \\
\text { pneumonia } \\
\text { dataset [98] }\end{array}$ & $\begin{array}{l}\text { 18,567 (COVID-19 } \\
\quad=140, \text { viral } \\
\text { pneumonia }=9576 \\
\text { normal }=8851)\end{array}$ & $\begin{array}{l}\text { COVID-19, } \\
\text { viral } \\
\text { pneumonia, } \\
\text { normal }\end{array}$ & $\begin{array}{c}\text { Training } \\
=16714 \\
\text { Test }=1862\end{array}$ & $\begin{array}{l}\text { ResNet101 } \\
\text { ResNet152 }\end{array}$ & Accuracy $=96.1 \%$ \\
\hline [91] & $\begin{array}{c}\text { Publicly } \\
\text { available } \\
\text { image } \\
\text { datasets } \\
\text { (chest X-ray } \\
\text { and CT } \\
\text { dataset) }[52,53]\end{array}$ & $\begin{array}{c}6087 \text { chest X-ray } \\
\text { and CT images } \\
\quad(\text { bacterial } \\
\text { pneumonia }=2780, \\
\text { coronavirus }=1493, \\
\text { COVID19 }=231 \\
\text { normal }=1583 \text { ) }\end{array}$ & $\begin{array}{l}\text { Normal, } \\
\text { bacteria, } \\
\text { coronavirus }\end{array}$ & $\begin{array}{l}\text { Training }=80 \% \\
\quad \text { Validation } \\
\quad=20 \%\end{array}$ & $\begin{array}{c}\text { VGG16, } \\
\text { VGG19, } \\
\text { DenseNet201, } \\
\text { Incep- } \\
\text { tion_ResNet_V2, } \\
\text { Inception_V3, } \\
\text { Resnet50, } \\
\text { MobileNet_V2 }\end{array}$ & Accuracy $=92.18 \%$ \\
\hline
\end{tabular}

\subsubsection{Custom Deep Learning Techniques}

The work in [99] introduced an ensemble deep learning model for novel COVID19 detection from CT images. The ensemble classifier, EDL-COVID, is based on three deep convolutional neural network models: AlexNet, GoogleNet, and ResNet. The used dataset consisted of 2500 CT images of lung tumors and 2500 normal lungs. The proposed model was evaluated using 5-fold cross validation. EDL-COVID obtained an accuracy, sensitivity, specificity, F-measure, and MCC of 99.054\%, 99.05\%, 99.6\%, 98.59\%, and 97.89\%, respectively.

Authors of another study suggested a deep learning diagnostic assistance system for COVID-19 detection using chest radiographs [100]. The system employed a modified and expanded version of COVID-deep net's learning algorithm. Five open-access databases were used to compile the data. Following data harmonization, the training set included 7966 normal cases, 5451 with other pneumonia, and 258 CXRs with COVID-19 pneumonia, where each group was represented by 100 cases in the testing dataset. The overall diagnostic accuracy for the suggested approach was $94.3 \%$.

To distinguish the infected cases from the normal or pneumonia cases, other authors [13] used the modified ResNet18-based convolution neural networks with chest X-ray 
images. In this system, 15,085 X-ray images were used for the diagnosis. The dataset was split using 3-fold cross validation. The proposed model obtained an accuracy of 96.73\%, recall of $94 \%$, and specificity of $100 \%$ for the three classes (normal, pneumonia, and COVID19). In another study [101], a computer aided diagnostic (CAD) framework comprised of two deep learning models (discrimination-DL and localization-DL) were proposed. The used dataset consisted in 3545 chest X-ray samples where 204 samples were COVID-19 cases, 2004 samples were CAP cases, and 1314 samples were healthy people. To obtain a better performance, the dataset was divided into a $80 \%$ for training and $20 \%$ for validation, and 61 images were collected from 21 COVID-19 patients, 20 CAP patients, and 20 controls, which were used in the testing phase to prove the model generalization. The final CAD scheme achieved a test accuracy of $93.65 \%$, sensitivity of $90.92 \%$, and specificity of $92.62 \%$.

The authors of [102] introduced a deep learning approach (CNN with five convolutional layers) for COVID-19 and viral pneumonia screening using X-ray images. In the study, X-ray images were collected from Kaggle [53,92]. The used dataset contained 1389 images. The proposed deep learning model produced an average classification accuracy of $90.64 \%$ and an F1 score of $89.8 \%$ after performing 5 -fold cross validation on a multi-class dataset consisting of COVID-19, viral pneumonia, and normal X-ray images.

The authors of [103] described two deep learning architectures for automatically detecting COVID-19-positive patients using chest CT X-ray pictures. The modified AlexNet (mAlexNet) architecture was the first proposed architecture. AlexNet is made up of 25 layers, one of which is a convolution layer. Bidirectional long short-term memories (BiLSTM) is the second architecture. A total of 2905 chest X-ray images were used in the study. The authors employed a variety of indicators to assess their proposed models. With a $98.70 \%$ accuracy, BiLSTM outperformed AlexNet.

The authors of [104] suggested an integrated stacked deep convolution network, InstaCovNet-19. To compensate for the small size of training dataset, the created system utilized different pre-trained models, ResNet101, Xception, InceptionV3, MobileNet, and NASNet. The suggested approach used X-ray images of a sick person's chest to detect COVID-19 and pneumonia. There were 361 verified COVID-19 instances, 1341 pneumonia cases, and 1345 normal cases among the 3047 chest X-rays. The dataset was partitioned into a training and testing set a a ratio of $80 \%$ and $20 \%$, respectively. The proposed model achieved an accuracy of $99.08 \%$ for the three classes (COVID-19, pneumonia, and normal), while achieving an accuracy of $99.53 \%$ for two classes (COVID-19, healthy). The proposed system achieved an average recall, F1 score, and precision of 99\%, 99\%, and 99\%, respectively, for multi classification, while achieving a $100 \%$ precision and a recall of $99 \%$ for the binary classification.

The authors of [105] used shuffled residual CNN to determine different filters for COVID-19 detection from chest X-rays. The proposed work included two CNN architectures: channel-shuffled dual-branched (CSDB) CNN and CSDB CNN with a distinctive filter learning (DFL) paradigm. In the study, a total of 3047 chest X-ray images were taken, where 10,434 were from healthy people (normal), 558 were COVID-19 cases, 2780 were bacterial pneumonia cases, and 1493 cases were viral pneumonia diseases. In this scheme, the dataset was partitioned using a 5-fold cross-validation technique. The proposed system (customized CNN with a distinctive filter learning module) obtained an F1 score of 97.20\% and an accuracy of $99.80 \%$ for the COVID-19 X-ray set.

The authors of [106] proposed binary and multi-classification deep learning models. The acquired data were divided into two sets: training and testing, at $80 \%$ and $20 \%$ respectively. The binary model had a precision of $98.7 \%$, while the three-class model had an accuracy of $98.3 \%$.

The author of [107] described an MH-COVIDNet system that used deep neural networks and meta-heuristic-based feature selection on X-ray images to diagnose COVID-19. A dataset of 364 X-ray images of COVID-19, normal, and pneumonia, was constructed for this investigation, with each class having 364 images. The 5-fold cross-validation approach was used to partition the dataset. The accuracy of MH-COVIDNet was $99.38 \%$. 
In another research work [108], a novel CNN model called CoroDet was introduced for the automatic detection of COVID-19 using raw chest X-ray and CT scan images. CoroDet was developed to serve as an accurate diagnostic for binary and multi-classes. A total of 7390 images were considered for the experiment. The dataset was divided using the 5-fold cross-validation method. The twenty-two-layer CNN model achieved an accuracy of 99.1\% for binary classification, $94.2 \%$ for three classes, and $91.2 \%$ for four classes.

In [24], COVIDCTNet, an open-source deep learning technique for diagnosing COVID19 based on a small cohort of CT images was suggested. In the CNN evaluation, the dataset was split at $95 \%$ for the training the algorithm and $5 \%$ for validating the model in the hold-out. During the validation phase, the suggested system achieved a detection accuracy of $93.33 \%$ of COVID-19 versus non-COVID-19 (two classes) and a multi-classification accuracy of $86.66 \%$ was achieved. To test the classification quality of the model, an independent dataset consisting of 20 mixed cases of control, COVID-19, and CAP was used. COVIDCTNet achieved an accuracy of 95\% for two classes (COVID-19 cases, non- COVID-19) and an accuracy of $85 \%$ for three classes.

In another work [109] a novel COVID-19-assisted diagnosis schema, based on a convolution neural network, was proposed. The COVID-19 dataset was composed of 1184 X-ray images of COVID-19, MERS SARS, ARDS illnesses, and normal cases. All of the data were divided into two categories: training (757 images) and testing (427 images). The network obtained an accuracy, precision, recall, and F1 score of 98\%, 99\%, 98\%, and 98\%, respectively.

In [110], the Convid-Net deep convolutional neural network (CNN) framework for detecting COVID-19 from chest X-ray pictures, which was based on a combination of a residual network and parallel convolution. In the work, the dataset was retrieved from different publicly available sources, consisting of a total of 1440 COVID-19 images, 2470 normal images, and 2407 chest X-ray images of viral and bacterial pneumonia. ConvidNet achieved an accuracy of $97.99 \%$. The authors of [111] suggested a lightweight deep convolutional neural network for chest X-rays. The proposed architecture was inspired by InceptionV3, InceptionResNetV2, and MobileNetV2. The dataset was collected from three different open access datasets. The used data were partitioned into 20,907 training samples and 231 testing samples. The proposed model achieved a 95\% accuracy for multiclassification.

DeepCoroNet, a method based on a deep LSTM model for automatically identifying COVID-19 instances from X-ray pictures, was introduced in [112]. To execute the experiment, different ratios of training and testing datasets (60:40\%, 70:30\%, and 80:20\%) were used. The best results were obtained with an $80 \%$ training rate and a $20 \%$ testing rate. All performance criteria were met by the network, which included accuracy, sensitivity, specificity, and F score.

In another study, the authors of [113] established a deep learning framework for detecting COVID-19 in X-ray and computed tomography images. ResBlock-A, ResBlock-B, and Control Gate Block made up a modular CNN-based classification system. The data for the study were gathered from a variety of sources. The suggested system used 9830 images for training and 547 images for testing from the total dataset. The trial results yielded an F1 score of $98.90 \%$ and a specificity of $100 \%$.

In [114], COVID-19 infected cases from four other classes, normal, tuberculosis (TB), bacterial pneumonia (BP), and viral pneumonia (VP), were classified using a deep learning technique CNN named MANet. The proposed system contained a two-stage segmentation using the UNet model with a ResNet backbone and classification was performed by including four classic CNNs (ResNet34, ResNet50, VGG16, and Inceptionv3). The datasets were collected from three public CXR data repositories, and consisted of CXR images from five classes, normal, COVID-19, TB, BP, and VP with 1840, 433, 394, 2780, and 1345 images, respectively. ResNet50 with MA scored the highest average test accuracy of $96.32 \%$ in three runs, and the highest one was $97.06 \%$, among the tested classification models. 
The authors of [115] presented COVID-19 detection utilizing deep learning models and structured chest $X$-ray images using fuzzy color and stacking algorithms to exploit social mimic optimization. In the study, the dataset consisted of three classes; namely, coronavirus, pneumonia, and normal X-ray imagery. In preprocessing, the dataset was reconstructed using the fuzzy technique and the stacking technique. The MobileNetV2 and SqueezeNet deep learning models were trained using the stacked dataset. The obtained feature sets were classified using the SVM method. The dataset was split up into $70 \%$ and $30 \%$ for the training and testing sets, respectively. For the experimentation related to the stacked dataset, the k-fold cross-validation method was used. The proposed approach achieved an overall accuracy of $99.27 \%$.

Using chest X-rays, in [116], a confidence-aware anomaly detection (CAAD) model was developed to differentiate viral pneumonia cases from non-viral pneumonia cases and healthy controls. The X-VIRAL and XCOVID X-ray image collections were used in this work. There were 5977 instances of viral pneumonia, 18,619 cases of non-viral pneumonia, and 18,774 healthy controls in the X-VIRAL dataset (5977 positive and 37,393 negative cases). A total of 106 verified COVID-19 cases and 107 healthy controls made up the X-COVID set. For external validation, a public COVID-19 dataset called Open-COVID was employed. The X-ray images of 493 confirmed COVID-19 patients, 16 confirmed SARS cases, and 10 confirmed MERS cases were included in the dataset. During testing, the proposed design achieved an AUC of $83.61 \%$ and had a sensitivity of $71.70 \%$.

CVDNet is a unique deep learning architecture created by the authors of [117] for identification of coronavirus (COVID-19) from chest X-ray images. The convolutional neural network (CNN) model was trained on a dataset that included 219 COVID-19, 1341 normal, and 1345 viral pneumonia chest X-ray images, and which is publicly available. The dataset was separated into three classes using the 5-fold cross-validation procedure. To classify COVID-19, normal, and viral pneumonia, the proposed model had an average accuracy of $97.20 \%$.

Table 8 summarizes the deep learning models for multi-class classification utilizing a pre-trained model with deep transfer learning for the COVID-19 dataset. Different medical imaging modalities were used in the DL techniques (computer tomography (CT) and chest X-rays (CXR)).

Table 8. Summary of deep learning based COVID-19 multi-classification using custom models.

\begin{tabular}{|c|c|c|c|c|c|c|}
\hline Authors & Data Sources & No. of Images & $\begin{array}{l}\text { Name of } \\
\text { Classes }\end{array}$ & Partitioning & Techniques & Performances (\%) \\
\hline [99] & $\begin{array}{l}\text { Journals: Science } \\
\text { direct, Nature, } \\
\text { Springer Link, and } \\
\text { China CNKI, } \\
\text { Thoritative media } \\
\text { reports: New York } \\
\text { Times, Daily Mail } \\
\text { (United Kingdom), } \\
\text { The Times (United } \\
\text { Kingdom), } \\
\text { CNN, etc. }\end{array}$ & $\begin{array}{l}2933 \text { lung CT } \\
\text { images }\end{array}$ & $\begin{array}{l}\text { COVID, } \\
\text { lung tumor, } \\
\text { normal lung }\end{array}$ & $\begin{array}{l}\text { Training } \\
\quad=6000 \\
\text { Test }=1500 \\
\text { 5-fold cross } \\
\text { validation. }\end{array}$ & EDL-COVID & $\begin{array}{c}\text { Accuracy } \\
=99.054 \% . \\
\text { Sensitivity }=99.05 \% \\
\text { Specificity }=99.6 \% \\
\text { F measure }=98.59 \% \\
\text { MCC }=97.89 \%\end{array}$ \\
\hline [100] & $\begin{array}{c}\text { Multiple sources } \\
{[4,53,81,98,118]}\end{array}$ & $\begin{array}{c}\text { 13,975 CXR } \\
\text { images (normal } \\
=7966, \\
\text { pneumonia } \\
=5451, \text { and } \\
\text { COVID-19 } \\
\text { pneumonia = 258) }\end{array}$ & $\begin{array}{l}\text { Healthy, } \\
\text { pneumonia, } \\
\text { COVID-19 }\end{array}$ & $\begin{array}{c}\text { Training } \\
=13,675 \\
\text { Test }=300\end{array}$ & $\begin{array}{l}\text { Modified } \\
\text { COVID-net }\end{array}$ & $\begin{array}{c}\text { Accuracy }=94.3 \% \\
\text { Sensitivity }=94.3 \% \\
\pm 4.5 \% \\
\text { Specificity }=97.2 \% \\
\pm 1.9 \% \\
\text { PPV }=94.5 \% \\
\pm 3.3 \% \\
\text { F score }=94.3 \% \\
\pm 2.0 \%\end{array}$ \\
\hline
\end{tabular}


Table 8. Cont.

\begin{tabular}{|c|c|c|c|c|c|c|}
\hline Authors & Data Sources & No. of Images & $\begin{array}{l}\text { Name of } \\
\text { Classes }\end{array}$ & Partitioning & Techniques & Performances (\%) \\
\hline [13] & $\begin{array}{c}\text { Two open-source } \\
\text { datasets }[52,53]\end{array}$ & $\begin{array}{c}15,085 \text { X-ray } \\
\text { (normal = 8851, } \\
\text { COVID-19=180, } \\
\text { pneumonia } \\
=6054 \text { ) }\end{array}$ & $\begin{array}{c}\text { Normal, } \\
\text { COVID-19, } \\
\text { pneumonia }\end{array}$ & $\begin{array}{l}\text { cross entropy } \\
3 \text {-fold cross } \\
\text { validation }\end{array}$ & $\begin{array}{l}\text { Modified } \\
\text { ResNet18 }\end{array}$ & $\begin{array}{c}\text { Accuracy }=96.73 \% \\
\text { Recall }=94 \% \\
\text { Specificity }=100 \%\end{array}$ \\
\hline [101] & $\begin{array}{c}\text { COVID-19 CXR } \\
\text { dataset [53], } \\
\text { Xiangya Hospital } \\
\text { RSNA pneumonia } \\
\text { detection } \\
\text { challenge [98] }\end{array}$ & $\begin{array}{c}3545 \text { chest } X \text {-ray } \\
\text { images } \\
(\text { COVID-19 }=204 \\
\text { healthy }=1314 \\
\text { CAP }=2004)\end{array}$ & $\begin{array}{l}\text { COVID-19, } \\
\text { Healthy, CAP }\end{array}$ & $\begin{array}{c}\text { Training }=80 \% \\
\text { Validation } \\
=20 \% \\
\text { Test }=61 \\
\text { images }\end{array}$ & $\begin{array}{l}\text { ResNet50 + } \\
\text { FPN }\end{array}$ & $\begin{array}{l}\text { Accuracy }=93.65 \% \\
\text { Sensitivity }=90.92 \% \\
\text { Specificity }=92.62 \%\end{array}$ \\
\hline [102] & $\begin{array}{c}\text { Two Kaggle } \\
\text { datasets }[53,92]\end{array}$ & $\begin{array}{c}1389 \text { X-ray } \\
\text { images } \\
\text { (COVID-19 = 289, } \\
\text { viral pneumonia } \\
=550, \text { normal } \\
=550)\end{array}$ & $\begin{array}{l}\text { COVID-19, } \\
\text { viral } \\
\text { pneumonia, } \\
\text { normal }\end{array}$ & $\begin{array}{l}5 \text {-fold cross } \\
\text { validation }\end{array}$ & $\mathrm{CNN}$ & $\begin{aligned} \text { Accuracy } & =90.64 \% \\
\text { F1 score } & =89.8 \%\end{aligned}$ \\
\hline [103] & $\begin{array}{l}\text { Open-access } \\
\text { database [4] }\end{array}$ & $\begin{array}{l}2905 \text { CXR images } \\
\text { (COVID-19=219, } \\
\text { viral pneumonia } \\
=1345, \text { normal } \\
=1341)\end{array}$ & $\begin{array}{l}\text { COVID-19, } \\
\text { viral } \\
\text { pneumonia, } \\
\text { normal }\end{array}$ & & mAlexNet & $\begin{array}{c}\text { Accuracy }=98.70 \% \\
\text { Error }=0.0130 \\
\text { Recall }=98.76 \% \\
\text { Specificity }=99.33 \% \\
\text { Precision }=98.77 \% \\
\text { False positive rate } \\
=0.0067 \\
\text { F1 score }=98.76 \% \\
\text { AUC }=99.00 \% \\
\text { MCC }=98.09 \% \\
\text { Kappa }=97.07 \%\end{array}$ \\
\hline [104] & $\begin{array}{l}\text { COVID-19 } \\
\text { Radiography } \\
\text { Database [4], } \\
\text { Chest X-ray } \\
\text { dataset [119] }\end{array}$ & $\begin{array}{l}3047 \text { chest X-ray } \\
\text { images } \\
\text { (COVID-19=361, } \\
\text { pneumonia } \\
=1341, \text { normal } \\
=1345)\end{array}$ & $\begin{array}{l}\text { COVID, } \\
\text { non-COVID } \\
\text { COVID-19, } \\
\text { pneumonia, } \\
\text { normal }\end{array}$ & $\begin{array}{l}\text { Training }=80 \% \\
\text { Test }=20 \%\end{array}$ & InstaCovNet-19 & $\begin{array}{c}\text { Two class: } \\
\text { Accuracy }=99.53 \% \\
\text { Precision }=100 \% \\
\text { Recall }=99 \% \\
\text { Three class: } \\
\text { Accuracy }=99.08 \% \\
\text { Recall }=99 \% \\
\text { F1 score }=99 \% \\
\text { Precision }=99 \%\end{array}$ \\
\hline [105] & $\begin{array}{c}\text { Multiple sources } \\
{[53,54,78,82,98,118,} \\
120]\end{array}$ & $\begin{array}{l}15,265 \text { chest } X \text {-ray } \\
\text { images } \\
\text { (COVID-19 }=558, \\
\text { normal }=10,434, \\
\text { bacterial } \\
\text { pneumonia } \\
=2780, \text { Viral } \\
\text { pneumonia } \\
=1493)\end{array}$ & $\begin{array}{l}\text { COVID-19, } \\
\text { normal, viral } \\
\text { pneumonia, } \\
\text { bacterial } \\
\text { pneumonia }\end{array}$ & $\begin{array}{l}\text { 5-fold cross } \\
\text { validation }\end{array}$ & CSDB CNN & $\begin{array}{c}\text { Precision }=96.34 \\
\text { Recall }=97.54 \% \\
\text { F1 score }=96.90 \% \\
\text { Accuracy }=97.94 \% \\
\text { Specificity }=99.25 \% \\
\text { AUC }=98.39 \%\end{array}$ \\
\hline [106] & $\begin{array}{l}\text { COVID-19 } \\
\text { dataset [53], } \\
\text { chest-X-ray } \\
\text { images [78] }\end{array}$ & $\begin{array}{c}\text { CXR (COVID-19 } \\
=145, \text { Bacterial } \\
\text { Pneumonia }=145, \\
\text { normal }=145)\end{array}$ & $\begin{array}{l}\text { COVID, } \\
\text { non-COVID } \\
\text { COVID, } \\
\text { non-COVID, } \\
\text { bacterial } \\
\text { pneumonia }\end{array}$ & $\begin{array}{c}\text { Training }=80 \% \\
\text { Test }=20 \%\end{array}$ & $\begin{array}{l}\text { deep learning } \\
\text { conditional } \\
\text { generative } \\
\text { adversarial } \\
\text { networks }\end{array}$ & $\begin{array}{c}\text { Two class: } \\
\text { Accuracy }=98.7 \% \\
\text { Sensitivity }=100 \% \\
\text { Specificity }=98.3 \% \\
\text { Three class: } \\
\text { Accuracy }=98.3 \% \\
\text { Sensitivity }=99.3 \% \\
\text { Specificity }=98.1 \%\end{array}$ \\
\hline
\end{tabular}


Table 8. Cont.

\begin{tabular}{|c|c|c|c|c|c|c|}
\hline Authors & Data Sources & No. of Images & $\begin{array}{l}\text { Name of } \\
\text { Classes }\end{array}$ & Partitioning & Techniques & Performances (\%) \\
\hline [107] & $\begin{array}{c}\text { Multiple } \\
\text { sources }[4,52,53]\end{array}$ & $\begin{array}{c}1092 \text { X-ray } \\
\text { images } \\
(\text { COVID-19 = 364, } \\
\text { normal 364, } \\
\text { pneumonia = 364) }\end{array}$ & $\begin{array}{l}\text { COVID-19, } \\
\text { normal } \\
\text { COVID-19, } \\
\text { normal, } \\
\text { pneumonia }\end{array}$ & $\begin{array}{c}\text { Training }=70 \% \\
\text { Test }=30 \% \\
5 \text {-fold cross } \\
\text { validation }\end{array}$ & $\begin{array}{c}\text { MH- } \\
\text { COVIDNet }\end{array}$ & Accuracy $=99.38 \%$ \\
\hline [108] & $\begin{array}{c}\text { Multiple } \\
\text { sources }[4,53,79,92, \\
118,120-122]\end{array}$ & $\begin{array}{l}7390 \text { X-ray and } \\
\text { CT images } \\
\text { (COVID-19 } \\
=2843, \text { normal } \\
=3108, \text { viral } \\
\text { pneumonia }+ \\
\text { bacterial } \\
\text { pneumonia } \\
=1439)\end{array}$ & $\begin{array}{c}\text { COVID, } \\
\text { normal } \\
\text { COVID, } \\
\text { normal, } \\
\text { pneumonia } \\
\text { COVID, } \\
\text { normal, viral } \\
\text { pneumonia, } \\
\text { bacterial } \\
\text { pneumonia }\end{array}$ & $\begin{array}{l}\text { 5-fold cross } \\
\text { validation }\end{array}$ & CoroDet & $\begin{array}{c}\text { Two class: } \\
\text { Accuracy }=99.1 \% \\
\text { Sensitivity }=95.36 \% \\
\text { Specificity }=97.36 \% \\
\text { Precision }=97.64 \% \\
\text { Recall }=95.3 \% \\
\text { F1 score }=96.88 \% \\
\text { Three class: } \\
\text { Accuracy }=94.2 \% \\
\text { Sensitivity }=92.76 \% \\
\text { Specificity }=94.56 \% \\
\text { Precision }=94.04 \% \\
\text { Recall }=92.5 \% \\
\text { F1 score }=91.32 \% \\
\text { Four class: } \\
\text { Accuracy }=91.2 \% \\
\text { Sensitivity }=91.76 \% \\
\text { Specificity }=93.48 \% \\
\text { Precision }=92.04 \% \\
\text { Recall }=91.9 \% \\
\text { F1 score }=90.04\end{array}$ \\
\hline [24] & $\begin{array}{l}\text { LUNGx Challenge } \\
\text { for computerized } \\
\text { lung nodule } \\
\text { classification [123] }\end{array}$ & $\begin{array}{c}\text { 16,750 CT images } \\
\text { (COVID-19 } \\
=5550, \text { CAP } \\
=5750, \text { control } \\
=5450)\end{array}$ & $\begin{array}{c}\text { COVID-19, } \\
\text { Non-COVID } \\
\text { COVID-19, } \\
\text { CAP, } \\
\text { control }\end{array}$ & $\begin{array}{l}\text { Training } \\
=15,000 \\
\text { Validation } \\
\quad=750 \\
\text { Test }=1000\end{array}$ & COVIDCTNet & $\begin{array}{c}\text { Sensitivity }=93 \% \\
\text { Specificity }=100 \% \\
\text { Two class: } \\
\text { Accuracy }=95 \% \\
\text { Three class: } \\
\text { Accuracy }=85 \%\end{array}$ \\
\hline [109] & $\begin{array}{l}\text { COVID-19 } \\
\text { dataset [53] }\end{array}$ & $\begin{array}{c}1184 \text { chest } \text { X-ray } \\
\text { images } \\
(\text { COVID-19 }=336 \\
\text { MERS }=185 \\
\text { SARS }=141 \\
\text { ARDS }=130 \\
\text { Normal }=392)\end{array}$ & $\begin{array}{l}\text { COVID-19, } \\
\text { MERS, SARS, } \\
\text { ARDS, normal }\end{array}$ & $\begin{array}{l}\text { Training }=757 \\
\text { Test }=427\end{array}$ & $\mathrm{CNN}$ & $\begin{array}{c}\text { Accuracy }=98 \% \\
\text { Precision }=99 \% \\
\text { Recall }=98 \% \\
\text { F1 score }=98 \%\end{array}$ \\
\hline [110] & $\begin{array}{c}\text { Multiple } \\
\text { sources }[53,81,92, \\
118,122,124,125]\end{array}$ & $\begin{array}{c}6317 \text { chest X-ray } \\
\text { images } \\
\text { (COVID-19 } \\
=1440, \text { normal } \\
=2470 \text { viral and } \\
\text { bacterial } \\
\text { pneumonia } \\
=2407)\end{array}$ & $\begin{array}{l}\text { COVID-19, } \\
\text { normal, } \\
\text { pneumonia }\end{array}$ & $\begin{array}{l}\text { Training }=70 \% \\
\text { Test }=30 \%\end{array}$ & Convid-Net & Accuracy $=97.99 \%$ \\
\hline
\end{tabular}


Table 8. Cont.

\begin{tabular}{|c|c|c|c|c|c|c|}
\hline Authors & Data Sources & No. of Images & $\begin{array}{l}\text { Name of } \\
\text { Classes }\end{array}$ & Partitioning & Techniques & Performances (\%) \\
\hline [111] & $\begin{array}{l}\text { COVID-19 Image } \\
\text { Data } \\
\text { Collection [53], } \\
\text { RSNA Pneumonia } \\
\text { Detection } \\
\text { Challenge } \\
\text { dataset [98], } \\
\text { COVID-19 Chest } \\
\text { X-ray Dataset } \\
\text { Initiative [120] }\end{array}$ & $\begin{array}{l}13,862 \text { chest } X \text {-ray } \\
\text { samples } \\
\text { (COVID- } 19=245 \\
\text { pneumonia } \\
=5551, \text { normal } \\
=8066)\end{array}$ & $\begin{array}{l}\text { COVID-19, } \\
\text { pneumonia, } \\
\text { normal }\end{array}$ & $\begin{array}{l}\text { Training } \\
=20,907 \\
\text { Test }=231\end{array}$ & Corona-Nidaan & $\begin{array}{c}\text { For three-class } \\
\text { classification: } \\
\text { Accuracy = 95\% } \\
\text { For COVID-19 } \\
\text { cases: } \\
\text { Precision }=94 \% \\
\text { Recall }=94 \%\end{array}$ \\
\hline [112] & {$[78,126,127]$} & $\begin{array}{c}1061 \text { CX images } \\
(\text { COVID-19 = 361, } \\
\text { normal = 200, } \\
\text { pneumonia }=500)\end{array}$ & $\begin{array}{l}\text { COVID-19, } \\
\text { pneumonia, } \\
\text { normal }\end{array}$ & $\begin{array}{l}\text { Training }=80 \% \\
\text { Testing }=20 \%\end{array}$ & DeepCoroNet & $\begin{array}{c}\text { Accuracy }=100 \% \\
\text { Sensitivity }=100 \% \\
\text { Specificity }=100 \% \\
\text { F score }=100 \%\end{array}$ \\
\hline [113] & $\begin{array}{c}\text { Multiple sources } \\
{[53,74,98,128]}\end{array}$ & $\begin{array}{c}\text { 10,377 X-ray and } \\
\text { CT images } \\
\text { (normal, } \\
\text { pneumonia, } \\
\text { COVID-19, } \\
\text { influenza) }\end{array}$ & $\begin{array}{l}\text { COVID-19, } \\
\text { pneumonia, } \\
\text { normal }\end{array}$ & $\begin{array}{l}\text { Training } \\
=9830 \\
\text { Test }=547\end{array}$ & CNNRF & $\begin{array}{l}\text { F1 score }=98.90 \% \\
\text { Specificity }=100 \%\end{array}$ \\
\hline [114] & $\begin{array}{c}\text { Multiple sources } \\
{[52,53,129,130]}\end{array}$ & $\begin{array}{c}6792 \text { CXR images } \\
\text { (normal }=1840 \\
\text { COVID-19=433, } \\
\text { TB }=394, \mathrm{BP} \\
=2780, \mathrm{VP} \\
=1345)\end{array}$ & $\begin{array}{c}\text { COVID-19, } \\
\text { normal, } \\
\text { tuberculosis } \\
\text { (TB), bacterial } \\
\text { pneumonia } \\
\text { (BP), } \\
\text { viral } \\
\text { pneumonia } \\
\text { (VP) }\end{array}$ & $\begin{array}{c}\text { Training }=80 \% \\
\text { Validation } \\
=10 \% \\
\text { Test }=10 \%\end{array}$ & MANet & Accuracy $=96.32 \%$ \\
\hline [115] & $\begin{array}{c}\text { COVID-19 } \\
\text { dataset [4], Joseph } \\
\text { Paul Cohen } \\
\text { dataset [53] }\end{array}$ & $\begin{array}{c}458 \text { X-ray images } \\
(\text { COVID-19 }=295 \\
\text { pneumonia }=98 \\
\text { normal }=65)\end{array}$ & $\begin{array}{l}\text { COVID-19, } \\
\text { pneumonia, } \\
\text { normal }\end{array}$ & $\begin{array}{c}\text { Training }=70 \% \\
\text { Test }=30 \% \\
5 \text {-fold cross } \\
\text { validation }\end{array}$ & $\begin{array}{c}\text { MobileNetV2 + } \\
\text { SqueezeNet }\end{array}$ & Accuracy $=99.27 \%$ \\
\hline [116] & $\begin{array}{c}\text { X-VIRAL dataset } \\
\text { collected from } 390 \\
\text { township hospitals } \\
\text { through a } \\
\text { telemedicine } \\
\text { platform of JF } \\
\text { Healthcare, } \\
\text { X-COVID dataset } \\
\text { collected from } 6 \\
\text { institutions, } \\
\text { COVID-19 } \\
\text { dataset [53] }\end{array}$ & $\begin{array}{c}\text { Chest X-ray } \\
\text { images (positive } \\
\text { viral pneumonia } \\
=5977, \text { non-viral } \\
\text { pneumonia or } \\
\text { healthy }=37,393, \\
\text { COVID-19=106, } \\
\text { normal controls } \\
=107 \text { ) }\end{array}$ & $\begin{array}{c}\text { COVID, } \\
\text { non-COVID } \\
\text { COVID, SARS, } \\
\text { MERS }\end{array}$ & $\begin{array}{l}\text { 5-fold cross } \\
\text { validation }\end{array}$ & CAAD & $\begin{array}{c}\text { X-COVID dataset: } \\
\text { Two class } \\
\text { AUC }=83.61 \% \\
\text { Sensitivity }=71.70 \% \\
\text { Open-COVID } \\
\text { dataset: Three class } \\
\text { Accuracy = 94.93\% } \\
\text { for COVID-19 } \\
\text { detection } \\
\text { Accuracy = } 100 \% \\
\text { for SARS and } \\
\text { MERS detection }\end{array}$ \\
\hline [117] & $\begin{array}{l}\text { COVID-19 } \\
\text { Radiography } \\
\text { Database [4] }\end{array}$ & $\begin{array}{l}2905 \text { chest X-ray } \\
\text { images } \\
\text { (COVID-19 = 219, } \\
\text { viral pneumonia } \\
=1341, \text { normal } \\
=1345)\end{array}$ & $\begin{array}{l}\text { COVID, } \\
\text { viral } \\
\text { pneumonia, } \\
\text { normal }\end{array}$ & $\begin{array}{l}5 \text {-fold cross } \\
\text { validation } \\
\text { Training }=70 \% \\
\text { Validation } \\
=10 \% \text { Test } \\
=20 \%\end{array}$ & CVDNet & $\begin{array}{c}\text { Precision }=96.72 \% \\
\text { Accuracy }=96.69 \% \\
\text { Recall }=96.84 \% \\
\text { F1 score }=96.68 \% \\
\text { Accuracy }=97.20 \% \\
\text { for COVID-19 class }\end{array}$ \\
\hline
\end{tabular}




\section{Discussion: Challenge and Future Research Direction}

This section provides some directions can be utilized in future research in the detection and classification of coronavirus and enhance the efficiency of future deep learning classifiers. Some challenges were inspired by [131].

To begin, it is vital to emphasize that some studies examined, analyzed, and evaluated distinct datasets that were privately obtained by clinics, hospitals, or COVID research institutes. The main drawbacks of this are that it is difficult to go against the performance of these models in different studies.

Additionally, the training process plays an essential role in deep learning; to have a good model, huge amounts of training data are needed. At the start of the pandemic, the lack of datasets for training deep learning models for medical imaging (CT or X-rays) was a major challenge. In general, collecting and labeling large amounts of medical imaging data is difficult because it requires a great deal of time and effort by radiologists (experts). Several factors can be involved in collecting data, such as lighting conditions, different presentation characteristics of coloring, various sizes and views in different image modalities, and enlargement. It is important to consider the influence of clinical situations and collection techniques on the robustness of a dataset.

In the reviewed COVID-19 applications, authors used the classification of COVID-19 based on the supervised learning method. With this approach, training the models with tagged images led to better results. From the beginning of December 2019, the outbreak of COVID-19 has put health care systems under tremendous pressure. Thus, it is difficult to gather images of correct indications of COVID-19 that have been labeled by professional doctors. Generally, there are a number of unidentified clinical images that are accessible. These unlabeled images are a major source of knowledge and cannot be used for supervised learning. Hence, a classification model for COVID-19 is desperately needed and can be trained using several of clustering methods without supervision [132].

Another limitation in some studies is the use of data augmentation approaches rather than transfer learning to prevent over fitting. Most research studies applied data augmentation techniques, including translation, horizontal (and vertical) flipping, and random rotation to avoid the over fitting and to enhance the accuracy of model predictions [133]. Data augmentation is a good tool to solve the problems of unbalanced data or a lack of data; it can generate new images that retain the original features.

An additional concern is data leaking, which is one of the most serious and widespread issues in machine learning, as well as in deep learning. The most of the time, it can occur in the feature engineering stage in the pre-processing phase. Generally, this problem is caused by missing values, temporal data, and the normalization of data. In the context of training dataset using CT or CXR images, the normalization stage of the whole dataset [24] can be applied before splitting, and, at that time, a part of the information from the training and testing dataset can be shared. Unfortunately, during the splitting phase, there is no guarantee that all images from one patient will be placed into one sample set because all the samples are taken at random without any restriction. Data leakage can be avoided by properly performing cross validation.

Finally, the absence of benchmarks for COVID-19 classification systems based on deep learning was viewed as a challenge and resulted in an absence of flexibility.

Diagnosis and treatment of COVID-19 is essential. In the absence of a good cure, we just need to identify additional AI-based DL techniques for the early detection of COVID-19.

In order to prevent disease and the progression of the pandemic, it is necessary to detect and diagnose COVID-19 quickly using DL applications at the lowest cost and with few complications. The integration of DL techniques in radiology centers enables rapid and accurate diagnoses of pneumonia, especially in cases of COVID-19. The incorporation of DL methods in healthcare systems aids in decision making and a reduction in human error.

The majority of research on deep learning techniques, distinguishes COVID-19infected cases from the other classes, such as normal, tuberculosis (TB), bacterial pneumonia (BP), and viral pneumonia (VP) cases. 
The World Health Organization (WHO) designated certain Pango lineages as variations of concern (VOC) and assigned Greek letter designations, such as alpha (Pango lineage designation B.1.1.7), beta (B.1.351), delta (B.1.167.2), and, most recently, omicron (B.1.1.529). There are variations among these strains that are more communicable and others that are even more difficult to detect using traditional diagnostic techniques. Currently, there is a pressing need to create deep learning algorithms that can accurately and swiftly detect and classify the many SARS-CoV-2 mutations.

The reinforcement learning methodology allows a deep learning model to learn from its environment. The development of a system based on reinforcement learning can convincingly increase the efficiency and performance of COVID-19-classification techniques using different modalities of medical images.

\section{Conclusions}

In conclusion, the review focused on approaches based on deep learning networks for automated COVID-19 detection. The algorithms created in previous studies for the detection and classification of SARS-CoV-2, using deep learning approaches, with two imaging modalities (CT and X-ray samples), are described in this paper. Several studies have combined multiple datasets and used them in DL models to improve COVID-19detection performance. In this paper, we collected sources of used datasets that can be easily accessed by researchers. The major challenge was absence of benchmarks for COVID19 classification systems based on deep learning. We desperately need to develop deep learning systems with a higher performance in identifying COVID-19 at an early stage and that supports radiologists in their diagnoses.

Author Contributions: Conceptualization, I.J. and H.D.; methodology, L.A.; software, G.H.; validation, I.J., H.D. and E.O.; formal analysis, A.M.; investigation, M.H.; resources, L.A.; data curation, H.D.; writing-original draft preparation, L.A.; writing-review and editing, I.J. and H.D.; visualization, E.O., A.M. and M.H.; supervision, I.J. and H.D.; project administration, I.J. and H.D.; funding acquisition, H.D., E.O. and A.M., All authors have read and agreed to the published version of the manuscript.

Funding: The authors extend their appreciation to the Deanship of Scientific Research at King Saud University for funding this work through research group No. RG-1438-071.

Institutional Review Board Statement: Not applicable.

Informed Consent Statement: Not applicable.

Data Availability Statement: Not applicable.

Acknowledgments: This work was supported by the Deanship of Scientific Research at King Saud University, Saudi Arabia through the Research Group under Grant RG-1438-071.

Conflicts of Interest: The authors declare no conflict of interest.

\section{References}

1. Hu, T.; Liu, Y.; Zhao, M.; Zhuang, Q.; Xu, L.; He, Q. A comparison of COVID-19, SARS and MERS. PeerJ 2020, 8, e9725. [CrossRef] [PubMed]

2. Hani, C.; Trieu, N.; Saab, I.; Dangeard, S.; Bennani, S.; Chassagnon, G.; Revel, M.-P. COVID-19 pneumonia: A review of typical CT findings and differential diagnosis. Diagn. Interv. Imaging 2020, 101, 263-268. [CrossRef] [PubMed]

3. Zhang, Y.; Niu, S.; Qiu, Z.; Wei, Y.; Zhao, P.; Yao, J.; Huang, J.; Wu, Q.; Tan, M. COVID-da: Deep domain adaptation from typical pneumonia to COVID-19. arXiv 2020, arXiv:2005.01577.

4. Chowdhury, M.E.H.; Rahman, T.; Khandakar, A.; Mazhar, R.; Kadir, M.A.; Bin Mahbub, Z.; Islam, K.R.; Khan, M.S.; Iqbal, A.; Al Emadi, N.; et al. Can AI Help in Screening Viral and COVID-19 Pneumonia? IEEE Access 2020, 8, 132665-132676. [CrossRef]

5. Al-Doori, A.N.; Ahmed, D.S.; Kadhom, M.; Yousif, E. Herbal medicine as an alternative method to treat and prevent COVID-19. Baghdad J. Biochem. Appl. Biol. Sci. 2021, 2, 1-20. [CrossRef]

6. Galloway, S.E.; Paul, P.; MacCannell, D.R.; Johansson, M.A.; Brooks, J.T.; MacNeil, A.; Slayton, R.B.; Tong, S.; Silk, B.J.; Armstrong, G.L.; et al. Emergence of SARS-CoV-2 b. 1.1. 7 lineage-united states, december 29, 2020-january 12, 2021. Morb. Mortal. Wkly. Rep. 2021, 70, 95. [CrossRef] 
7. $\quad$ Madhi, S.A.; Baillie, V.; Cutland, C.L.; Voysey, M.; Koen, A.L.; Fairlie, L.; Padayachee, S.D.; Dheda, K.; Barnabas, S.L.; Bhorat, Q.E.; et al. Safety and efficacy of the ChAdOx1 nCoV-19 (AZD1222) COVID-19 vaccine against the B. 1.351 variant in South Africa. medRxiv 2021. [CrossRef]

8. Naveca, F.; da Costa, C.; Nascimento, V.; Souza, V.; Corado, A.; Nascimento, F.; Costa, Á.; Duarte, D.; Silva, G.; Mejía, M.; et al SARS-CoV-2 Reinfection by the New Variant of Concern (VOC) P. 1 in Amazonas, Brazil. 2021. Available online: Virological.org (accessed on 17 December 2021).

9. Boehm, E.; Kronig, I.; Neher, R.A.; Eckerle, I.; Vetter, P.; Kaiser, L. Novel SARS-CoV-2 variants: The pandemics within the pandemic. Clin. Microbiol. Infect. 2021, 27, 1109-1117. [CrossRef]

10. Hunter, P.R.; JBrainard, S.; Grant, A.R. The Impact of the November 2020 English National Lockdown on COVID-19 case counts. medRxiv 2021. [CrossRef]

11. Volz, E.; Mishra, S.; Chand, M.; Barrett, J.C.; Johnson, R.; Geidelberg, L.; Hinsley, W.R.; Laydon, D.J.; Dabrera, G.; O’Toole, Á.; et al. Transmission of SARS-CoV-2 Lineage B. 1.1. 7 in England: Insights from linking epidemiological and genetic data. medRxiv 2021. [CrossRef]

12. van Oosterhout, C.; Hall, N.; Ly, H.; Tyler, K.M. COVID-19 Evolution during the Pandemic-Implications of New SARS-CoV-2 Variants on Disease Control and Public Health Policies; Taylor \& Francis: Abingdon, UK, 2021.

13. Al-Falluji, R.A.; Katheeth, Z.D.; Alathari, B. Automatic Detection of COVID-19 Using Chest X-ray Images and Modified ResNet18Based Convolution Neural Networks. Comput. Mater. Contin. 2021, 66, 1301-1313. [CrossRef]

14. Zhang, J.; Xie, Y.; Li, Y.; Shen, C.; Xia, Y. COVID-19 screening on chest X-ray images using deep learning based anomaly detection. arXiv 2020, arXiv:2003.12338.

15. Assmus, A. Early history of $X$ rays. Beam Line 1995, 25, 10-24.

16. Schiaffino, S.; Tritella, S.; Cozzi, A.; Carriero, S.; Blandi, L.; Ferraris, L.; Sardanelli, F. Diagnostic performance of chest X-ray for COVID-19 pneumonia during the SARS-CoV-2 pandemic in Lombardy, Italy. J. Thorac. Imaging 2020, 35, W105-W106. [CrossRef] [PubMed]

17. Filler, A. The history, development and impact of computed imaging in neurological diagnosis and neurosurgery: CT, MRI, and DTI. Nat. Preced. 2009, 1. [CrossRef]

18. Suh, C.H.; Baek, J.H.; Choi, Y.J.; Lee, J.H. Performance of CT in the preoperative diagnosis of cervical lymph node metastasis in patients with papillary thyroid cancer: A systematic review and meta-analysis. Am. J. Neuroradiol. 2017, 38, 154-161. [CrossRef]

19. Eijsvoogel, N.G.; Hendriks, B.M.F.; Martens, B.; Gerretsen, S.C.; Gommers, S.; van Kuijk, S.M.J.; Mihl, C.; Wildberger, J.E.; Das, M. The performance of non-ECG gated chest CT for cardiac assessment-The cardiac pathologies in chest CT (CaPaCT) study. Eur. J. Radiol. 2020, 130, 109151. [CrossRef]

20. Herpe, G.; Lederlin, M.; Naudin, M.; Ohana, M.; Chaumoitre, K.; Gregory, J.; Vilgrain, V.; Freitag, C.A.; De Margerie-Mellon, C.; Flory, V.; et al. Efficacy of Chest CT for COVID-19 Pneumonia Diagnosis in France. Radiology 2021, 298, E81-E87. [CrossRef]

21. Kumar, P.R.; Manash, E.B.K. Deep learning: A branch of machine learning. J. Phys. Conf. Ser. 2019, 1228, 012045. [CrossRef]

22. Litjens, G.; Kooi, T.; Bejnordi, B.E.; Setio, A.A.A.; Ciompi, F.; Ghafoorian, M.; van der Laak, J.A.; van Ginneken, B.; Sánchez, C.I. A survey on deep learning in medical image analysis. Med. Image Anal. 2017, 42, 60-88. [CrossRef]

23. Zhang, H.; Zhang, J.; Zhang, H.; Nan, Y.; Zhao, Y.; Fu, E.; Xie, Y.; Liu, W.; Li, W.; Zhang, H.; et al. Automated detection and quantification of COVID-19 pneumonia: CT imaging analysis by a deep learning-based software. Eur. J. Nucl. Med. Mol. Imaging 2020, 47, 2525-2532. [CrossRef] [PubMed]

24. Javaheri, T.; Homayounfar, M.; Amoozgar, Z.; Reiazi, R.; Homayounieh, F.; Abbas, E.; Laali, A.; Radmard, A.R.; Gharib, M.H.; Mousavi, S.A.J.; et al. COVIDCTNet: An open-source deep learning approach to diagnose COVID-19 using small cohort of CT images. NPJ Digit. Med. 2021, 4, 29. [CrossRef]

25. Luz, E.; Silva, P.; Silva, R.; Silva, L.; Guimarães, J.; Miozzo, G.; Moreira, G.; Menotti, D. Towards an effective and efficient deep learning model for COVID-19 patterns detection in X-ray images. Res. Biomed. Eng. 2021. [CrossRef]

26. Pathak, Y.; Shukla, P.; Tiwari, A.; Stalin, S.; Singh, S. Deep Transfer Learning Based Classification Model for COVID-19 Disease IRBM 2020, in press. [CrossRef]

27. Gifani, P.; Shalbaf, A.; Vafaeezadeh, M. Automated detection of COVID-19 using ensemble of transfer learning with deep convolutional neural network based on CT scans. Int. J. Comput. Assist. Radiol. Surg. 2020, 16, 115-123. [CrossRef]

28. Lawton, S.; Viriri, S. Detection of COVID-19 from CT Lung Scans Using Transfer Learning. Comput. Intell. Neurosci. 2021, 2021, 5527923. [CrossRef]

29. Duran-Lopez, L.; Dominguez-Morales, J.; Corral-Jaime, J.; Vicente-Diaz, S.; Linares-Barranco, A. COVID-XNet: A Custom Deep Learning System to Diagnose and Locate COVID-19 in Chest X-ray Images. Appl. Sci. 2020, 10, 5683. [CrossRef]

30. Sakib, S.; Tazrin, T.; Fouda, M.M.; Fadlullah, Z.M.; Guizani, M. DL-CRC: Deep Learning-Based Chest Radiograph Classification for COVID-19 Detection: A Novel Approach. IEEE Access 2020, 8, 171575-171589. [CrossRef] [PubMed]

31. Dhahri, H.; Rabhi, B.; Chelbi, S.; Almutiry, O.; Mahmood, A.; Alimi, A.M. Automatic Detection of COVID-19 Using a Stacked Denoising Convolutional Autoencoder. Comput. Mater. Contin. 2021, 69, 3259-3274. [CrossRef]

32. Goodfellow, I.; Bengio, Y.; Courville, A.; Bengio, Y. Deep Learning; MIT Press: Cambridge, UK, 2016; Volume 1.

33. Schmidhuber, J. Deep Learning. Scholarpedia 2015, 10, 32832. [CrossRef]

34. Islam, Z.; Islam, M.; Asraf, A. A combined deep CNN-LSTM network for the detection of novel coronavirus (COVID-19) using X-ray images. Inform. Med. Unlocked 2020, 20, 100412. [CrossRef] [PubMed] 
35. Yang, B.; Guo, H.; Cao, E. Chapter Two-Design of Cyber-Physical-Social Systems with Forensic-Awareness Based on Deep Learning in AI and Cloud Computing; Hurson, A.R., Wu, S., Eds.; Elsevier: Amsterdam, The Netherlands, 2021; Volume 120, pp. 39-79.

36. Ke, Q.; Liu, J.; Bennamoun, M.; An, S.; Sohel, F.; Boussaid, F. Chapter 5-Computer Vision for Human-Machine Interaction. In Computer Vision for Assistive Healthcare; Leo, M., Farinella, G.M., Eds.; Academic Press: Cambridge, MA, USA, 2018; pp. 127-145.

37. Hcini, G.; Jdey, I.; Heni, A.; Ltifi, H. Hyperparameter optimization in customized convolutional neural network for blood cells classification. J. Theor. Appl. Inf. Technol. 2021, 99, 5425-5435.

38. Shamshirband, S.; Fathi, M.; Dehzangi, A.; Chronopoulos, A.T.; Alinejad-Rokny, H. A Review on Deep Learning Approaches in Healthcare Systems: Taxonomies, Challenges, and Open Issues. J. Biomed. Inform. 2020, 113, 103627. [CrossRef] [PubMed]

39. Hua, Y.; Guo, J.; Zhao, H. Deep belief networks and deep learning. In Proceedings of the 2015 International Conference on Intelligent Computing and Internet of Things, Harbin, China, 17-18 January 2015.

40. Hinton, G.E. Deep belief networks. Scholarpedia 2009, 4, 5947. [CrossRef]

41. Zong, K.; Luo, C. Reinforcement learning based framework for COVID-19 resource allocation. Comput. Ind. Eng. 2022, 167, 107960. [CrossRef] [PubMed]

42. Saood, A.; Hatem, I. COVID-19 lung CT image segmentation using deep learning methods: U-Net versus SegNet. BMC Med. Imaging 2021, 21, 19. [CrossRef]

43. Paluru, N.; Dayal, A.; Jenssen, H.B.; Sakinis, T.; Cenkeramaddi, L.R.; Prakash, J.; Yalavarthy, P.K. Anam-Net: Anamorphic Depth Embedding-Based Lightweight CNN for Segmentation of Anomalies in COVID-19 Chest CT Images. IEEE Trans. Neural Networks Learn. Syst. 2021, 32, 932-946. [CrossRef]

44. SYin, S.; Deng, H.; Xu, Z.; Zhu, Q.; Cheng, J. SD-UNet: A Novel Segmentation Framework for CT Images of Lung Infections Electronics 2022, 11, 130.

45. Shan, F.; Gao, Y.; Wang, J.; Shi, W.; Shi, N.; Han, M.; Xue, Z.; Shen, D.; Shi, Y. Abnormal lung quantification in chest CT images of COVID-19 patients with deep learning and its application to severity prediction. Med. Phys. 2020, 48, 1633-1645. [CrossRef]

46. Fung, D.L.X.; Liu, Q.; Zammit, J.; Leung, C.K.; Hu, P. Self-supervised deep learning model for COVID-19 lung CT image segmentation highlighting putative causal relationship among age, underlying disease and COVID-19. J. Transl. Med. 2021, 19, 1-18. [CrossRef]

47. Suri, J.; Agarwal, S.; Pathak, R.; Ketireddy, V.; Columbu, M.; Saba, L.; Gupta, S.; Faa, G.; Singh, I.; Turk, M.; et al. COVLIAS 1.0: Lung Segmentation in COVID-19 Computed Tomography Scans Using Hybrid Deep Learning Artificial Intelligence Models. Diagnostics 2021, 11, 1405. [CrossRef]

48. Hu, H.; Shen, L.; Guan, Q.; Li, X.; Zhou, Q.; Ruan, S. Deep co-supervision and attention fusion strategy for automatic COVID-19 lung infection segmentation on CT images. Pattern Recognit. 2021, 124, 108452. [CrossRef] [PubMed]

49. Kamil, M.Y. A deep learning framework to detect COVID-19 disease via chest X-ray and CT scan images. Int. J. Electr. Comput. Eng. IJECE 2021, 11, 844-850. [CrossRef]

50. Abdulmunem, A.A.; Abutiheen, Z.A.; Aleqabie, H.J. Recognition of corona virus disease (COVID-19) using deep learning network. Int. J. Electr. Comput. Eng. IJECE 2021, 11, 365-374. [CrossRef]

51. Gozes, O.; Frid-Adar, M.; Sagie, N.; Zhang, H.; Ji, W.; Greenspan, H. Coronavirus detection and analysis on chest ct with deep learning. arXiv 2020, arXiv:2004.02640.

52. Kermany, D.; Zhang, K.; Goldbaum, M. Labeled optical coherence tomography (OCT) and Chest X-ray images for classification. Mendeley Data 2018, 2, 2

53. Cohen, J.P.; Morrison, P.; Dao, L. COVID-19 Image Data Collection. arXiv 2020, arXiv:2003.11597.

54. Italian Society of Medical and Interventional Radiology (SIRM). 2020. Available online: https://www.sirm.org/en/category/ articles / covid-19-database/page/1/ (accessed on 3 June 2020).

55. Manapure, P.; Likhar, K.; Kosare, H. Detecting COVID-19 in X-ray Images with Keras, Tensor Flow, and Deep Learning. Available online: http:/ / acors.org/Journal/Papers/Volume1/issue3/VOL1_ISSUE3_09.pdf (accessed on 17 December 2021).

56. ChainZ. Available online: www.ChainZ.cn (accessed on 17 December 2021).

57. Zhang, Y.-D.; Satapathy, S.C.; Liu, S.; Li, G.-R. A five-layer deep convolutional neural network with stochastic pooling for chest CT-based COVID-19 diagnosis. Mach. Vis. Appl. 2020, 32, 1-13. [CrossRef]

58. Ahrabi, S.S.; Scarpiniti, M.; Baccarelli, E.; Momenzadeh, A. An Accuracy vs. Complexity Comparison of Deep Learning Architectures for the Detection of COVID-19 Disease. Computation 2021, 9, 3. [CrossRef]

59. Zhu, Z.; Xingming, Z.; Tao, G.; Dan, T.; Li, J.; Chen, X.; Li, Y.; Zhou, Z.; Zhang, X.; Zhou, J.; et al. Classification of COVID-19 by Compressed Chest CT Image through Deep Learning on a Large Patients Cohort. Interdiscip. Sci. Comput. Life Sci. 2021, 13, 73-82. [CrossRef]

60. Siddiqui, S.Y.; Abbas, S.; Khan, M.A.; Naseer, I.; Masood, T.; Khan, K.M.; Al Ghamdi, M.A.; AlMotiri, S.H. Intelligent Decision Support System for COVID-19 Empowered with Deep Learning. Comput. Mater. Contin. 2021, 66, 1719-1732. [CrossRef]

61. Hajij, M.; Zamzmi, G.; Batayneh, F. TDA-Net: Fusion of Persistent Homology and Deep Learning Features for COVID-19 Detection in Chest X-ray Images. arXiv 2021, arXiv:2101.08398.

62. NIH. Nih Chest X-ray Dataset of 14 Common Thorax Disease. Available online: https://www.nih.gov/news-events/newsreleases/nih-clinical-center-provides-one-largestpublicly-available-chest-x-ray-datasets-scientific-community (accessed on 17 December 2021). 
63. Wang, S.; Kang, B.; Ma, J.; Zeng, X.; Xiao, M.; Guo, J.; Cai, M.; Yang, J.; Li, Y.; Meng, X.; et al. A deep learning algorithm using CT images to screen for Corona Virus Disease (COVID-19). Eur. Radiol. 2021, 31, 6096-6104. [CrossRef] [PubMed]

64. Rahimzadeh, M.; Attar, A.; Sakhaei, S.M. A fully automated deep learning-based network for detecting COVID-19 from a new and large lung CT scan dataset. Biomed. Signal Process. Control 2021, 68, 102588. [CrossRef]

65. Dhiman, G.; Chang, V.; Singh, K.K.; Shankar, A. ADOPT: Automatic deep learning and optimization-based approach for detection of novel coronavirus COVID-19 disease using X-ray images. J. Biomol. Struct. Dyn. 2021, 1-13. [CrossRef]

66. Yu, X.; Wang, S.-H.; Zhang, Y.-D. CGNet: A graph-knowledge embedded convolutional neural network for detection of pneumonia. Inf. Process. Manag. 2020, 58, 102411. [CrossRef]

67. Wehbe, R.M.; Sheng, J.; Dutta, S.; Chai, S.; Dravid, A.; Barutcu, S.; Wu, Y.; Cantrell, D.R.; Xiao, N.; Allen, B.D.; et al. DeepCOVIDXR: An Artificial Intelligence Algorithm to Detect COVID-19 on Chest Radiographs Trained and Tested on a Large US Clinical Data Set. Radiology 2021, 299, E167-E176. [CrossRef]

68. Sedik, A.; Hammad, M.; El-Samie, F.E.A.; Gupta, B.B.; El-Latif, A.A.A. Efficient deep learning approach for augmented detection of Coronavirus disease. Neural Comput. Appl. 2021, 1-18. [CrossRef]

69. Saha, P.; Sadi, M.S.; Islam, M. EMCNet: Automated COVID-19 diagnosis from X-ray images using convolutional neural network and ensemble of machine learning classifiers. Inform. Med. Unlocked 2020, 22, 100505. [CrossRef]

70. Jain, G.; Mittal, D.; Thakur, D.; Mittal, M.K. A deep learning approach to detect COVID-19 coronavirus with X-ray images. Biocybern. Biomed. Eng. 2020, 40, 1391-1405. [CrossRef]

71. Alom, M.Z.; Rahman, M.M.; Nasrin, M.S.; Taha, T.M.; Asari, V.K. COVID_MTNet: COVID-19 detection with multi-task deep learning approaches. arXiv 2020, arXiv:2004.03747.

72. Zheng, C.; Deng, X.; Fu, Q.; Zhou, Q.; Feng, J.; Ma, H.; Liu, W.; Wang, X. Deep learning-based detection for COVID-19 from chest CT using weak label. MedRxiv 2020. [CrossRef]

73. Shah, V.; Keniya, R.; Shridharani, A.; Punjabi, M.; Shah, J.; Mehendale, N. Diagnosis of COVID-19 using CT scan images and deep learning techniques. Emerg. Radiol. 2021, 28, 497-505. [CrossRef] [PubMed]

74. Clark, K.; Vendt, B.; Smith, K.; Freymann, J.; Kirby, J.; Koppel, P.; Moore, S.; Phillips, S.; Maffitt, D.; Pringle, M.; et al. The Cancer Imaging Archive (TCIA): Maintaining and Operating a Public Information Repository. J. Digit. Imaging 2013, 26, 1045-1057. [CrossRef]

75. Desai, S.; Baghal, A.; Wongsurawat, T.; Al-Shukri, S.; Gates, K.; Farmer, P.; Rutherford, M.; Blake, G.D.; Nolan, T.; Powell, T.; et al Data from chest imaging with clinical and genomic correlates representing a rural COVID-19 positive population. Cancer Imaging Arch. 2020. [CrossRef]

76. Zhao, J.; Zhang, Y.; He, X.; Xie, P. COVID-ct-dataset: A ct scan dataset about COVID-19. arXiv 2020, arXiv:2003.13865.

77. COVID-CTset. Available online: https://github.com/mr7495/COVID-CTset (accessed on 17 December 2021).

78. Chest X-ray Images (Pneumonia). 2020. Available online: https://www.kaggle.com/paultimothymooney/chest-xraypneumonia/version/1 (accessed on 17 December 2021)

79. UCSD-AI4H. COVID-CT. Available online: https://github.com/UCSD-AI4H/COVID-CT (accessed on 9 April 2020).

80. Alqudah, A.M.; Qazan, S. Augmented COVID-19 X-ray; Volume 4. 2020. Available online: https://data.mendeley.com/datasets/ 2fxz4px6d8/4 (accessed on 17 December 2021)

81. COVID-19 Radiography Database. Available online: https://www.kaggle.com/tawsifurrahman/covid19-radiography-database (accessed on 17 December 2021).

82. COVID-19 Radiopaedia. 2020. Available online: https:/ / radiopaedia.org/articles/covid-19-3?lang=us (accessed on 3 June 2020)

83. Bhatti, S.; Aziz, D.; Nadeem, D.; Usmani, I.; Aamir, P.; Khan, D. Automatic Classification of the Severity of COVID-19 Patients Based on CT Scans and X-rays Using Deep Learning. Eur. J. Mol. Clin. Med. 2021, 7, 1436-1455.

84. Afifi, A.; Hafsa, N.E.; Ali, M.A.S.; Alhumam, A.; Alsalman, S. An Ensemble of Global and Local-Attention Based Convolutional Neural Networks for COVID-19 Diagnosis on Chest X-ray Images. Symmetry 2021, 13, 113. [CrossRef]

85. Sarker, L.; Islam, M.M.; Hannan, T.; Ahmed, Z. COVID-Densenet: A Deep Learning Architecture to Detect COVID-19 from Chest Radiology Images. 2021. Available online: https:/ / pdfs.semanticscholar.org/c6f7/a57a37e87b52ac92402987c9b7a3df41f2db.pdf (accessed on 17 December 2021).

86. Karar, M.E.; Hemdan, E.E.-D.; Shouman, M.A. Cascaded deep learning classifiers for computer-aided diagnosis of COVID-19 and pneumonia diseases in X-ray scans. Complex Intell. Syst. 2020, 7, 235-247. [CrossRef]

87. Zebin, T.; Rezvy, S. COVID-19 detection and disease progression visualization: Deep learning on chest X-rays for classification and coarse localization. Appl. Intell. 2021, 51, 1010-1021. [CrossRef]

88. Ibrahim, A.U.; Ozsoz, M.; Serte, S.; Al-Turjman, F.; Yakoi, P.S. Pneumonia Classification Using Deep Learning from Chest X-ray Images During COVID-19. Cogn. Comput. 2021, 1-13. [CrossRef] [PubMed]

89. Jain, R.; Gupta, M.; Taneja, S.; Hemanth, D.J. Deep learning based detection and analysis of COVID-19 on chest X-ray images. Appl. Intell. 2020, 51, 1690-1700. [CrossRef] [PubMed]

90. Wang, N.; Liu, H.; Xu, C. Deep learning for the detection of COVID-19 using transfer learning and model integration. In Proceedings of the 2020 IEEE 10th International Conference on Electronics Information and Emergency Communication (ICEIEC), Beijing, China, 17-19 July 2020.

91. El Asnaoui, K.; Chawki, Y. Using X-ray images and deep learning for automated detection of coronavirus disease. J. Biomol. Struct. Dyn. 2020, 39, 3615-3626. [CrossRef] [PubMed] 
92. Sajid, N. COVID-19 Patients Lungs X-ray Images 10000. Available online: https://www.kaggle.com/nabeelsajid917/covid-19-xray-10000-images (accessed on 4 May 2020).

93. ABustos, A.; Pertusa, A.; Salinas, J.-M.; de la Iglesia-Vayá, M. PadChest: A large chest x-ray image dataset with multi-label annotated reports. arXiv 2019, arXiv:1901.07441.

94. DeGrave, A.J.; Janizek, J.D.; Lee, S.-I. AI for radiographic COVID-19 detection selects shortcuts over signal. Nat. Mach. Intell. 2021, 3, 610-619. [CrossRef]

95. Wang, L.; Lin, Z.Q.; Wong, A. COVID-net: A tailored deep convolutional neural network design for detection of COVID-19 cases from chest X-ray images. Sci. Rep. 2020, 10, 1-12. [CrossRef]

96. Novel Corona Virus 2019 Dataset. Available online: https://www.kaggle.com/sudalairajkumar/novel-corona-virus-2019-dataset (accessed on 17 December 2021).

97. Patel, P. Chest X-ray (COVID-19 \& Pneumonia). Available online: https://www.kaggle.com/prashant268/chest-xray-covid19pneumonia (accessed on 17 December 2021).

98. RSNA Pneumonia Detection Challenge. 2020. Available online: https://www.kaggle.com/c/rsna-pneumonia-detectionchallenge/data (accessed on 17 December 2021).

99. Zhou, T.; Lu, H.; Yang, Z.; Qiu, S.; Huo, B.; Dong, Y. The ensemble deep learning model for novel COVID-19 on CT images. Appl. Soft Comput. 2021, 98, 106885. [CrossRef]

100. Fontanellaz, M.; Ebner, L.; Huber, A.; Peters, A.; Löbelenz, L.; Hourscht, C.; Klaus, J.; Munz, J.; Ruder, T.; Drakopoulos, D.; et al. A Deep-Learning Diagnostic Support System for the Detection of COVID-19 Using Chest Radiographs: A Multireader Validation Study. Investig. Radiol. 2021, 56, 348-356. [CrossRef]

101. Wang, Z.; Xiao, Y.; Li, Y.; Zhang, J.; Lu, F.; Hou, M.; Liu, X. Automatically discriminating and localizing COVID-19 from community-acquired pneumonia on chest X-rays. Pattern Recognit. 2020, 110, 107613. [CrossRef]

102. Ahmed, F.; Bukhari, S.A.C.; Keshtkar, F. A Deep Learning Approach for COVID-19 8 Viral Pneumonia Screening with X-ray Images. Digit. Gov. Res. Pr. 2021, 2, 1-12. [CrossRef]

103. Aslan, M.F.; Unlersen, M.F.; Sabanci, K.; Durdu, A. CNN-based transfer learning-BiLSTM network: A novel approach for COVID-19 infection detection. Appl. Soft Comput. 2020, 98, 106912. [CrossRef] [PubMed]

104. Gupta, A.; Anjum; Gupta, S.; Katarya, R. InstaCovNet-19: A deep learning classification model for the detection of COVID-19 patients using Chest X-ray. Appl. Soft Comput. 2020, 99, 106859. [CrossRef] [PubMed]

105. Karthik, R.; Menaka, R.; Hariharan, M. Learning distinctive filters for COVID-19 detection from chest X-ray using shuffled residual CNN. Appl. Soft Comput. 2020,99, 106744. [CrossRef] [PubMed]

106. Karakanis, S.; Leontidis, G. Lightweight deep learning models for detecting COVID-19 from chest X-ray images. Comput. Biol. Med. 2020, 130, 104181. [CrossRef] [PubMed]

107. Canayaz, M. MH-COVIDNet: Diagnosis of COVID-19 using deep neural networks and meta-heuristic-based feature selection on X-ray images. Biomed. Signal Process. Control 2020, 64, 102257. [CrossRef]

108. EHussain, E.; Hasan, M.; Rahman, A.; Lee, I.; Tamanna, T.; Parvez, M.Z. CoroDet: A deep learning based classification for COVID-19 detection using chest X-ray images. Chaos Solitons Fractals 2020, 142, 110495. [CrossRef] [PubMed]

109. Mahdi, M.S.; Abid, Y.M.; Omran, A.H.; Abdul-Majeed, G. A Novel Aided Diagnosis Schema for COVID 19 Using Convolution Neural Network. IOP Conf. Ser. Mater. Sci. Eng. 2021, 1051, 012007. [CrossRef]

110. Ahmed, S.; Hossain, F.; Noor, M.B.T. Convid-Net: An Enhanced Convolutional Neural Network Framework for COVID-19 Detection from X-ray Images; Springer: Berlin/Heidelberg, Germany, 2020.

111. Chakraborty, M.; Dhavale, S.V.; Ingole, J. Corona-Nidaan: Lightweight deep convolutional neural network for chest X-ray based COVID-19 infection detection. Appl. Intell. 2021, 51, 3026-3043. [CrossRef]

112. Demir, F. DeepCoroNet: A deep LSTM approach for automated detection of COVID-19 cases from chest X-ray images. Appl. Soft Comput. 2021, 103, 107160. [CrossRef]

113. Liang, S.; Liu, H.; Gu, Y.; Guo, X.; Li, H.; Li, L.; Wu, Z.; Liu, M.; Tao, L. Fast automated detection of COVID-19 from medical images using convolutional neural networks. Commun. Biol. 2021, 4, 1-13. [CrossRef]

114. Xu, Y.; Lam, H.-K.; Jia, G. MANet: A two-stage deep learning method for classification of COVID-19 from Chest X-ray images. Neurocomputing 2021, 443, 96-105. [CrossRef] [PubMed]

115. Toğaçar, M.; Ergen, B.; Cömert, Z. COVID-19 detection using deep learning models to exploit Social Mimic Optimization and structured chest X-ray images using fuzzy color and stacking approaches. Comput. Biol. Med. 2020, 121, 103805. [CrossRef] [PubMed]

116. Zhang, J.; Xie, Y.; Pang, G.; Liao, Z.; Verjans, J.; Li, W.; Sun, Z.; He, J.; Li, Y.; Shen, C.; et al. Viral Pneumonia Screening on Chest X-Rays Using Confidence-Aware Anomaly Detection. IEEE Trans. Med. Imaging 2020, 40, 879-890. [CrossRef]

117. Ouchicha, C.; Ammor, O.; Meknassi, M. CVDNet: A novel deep learning architecture for detection of coronavirus (COVID-19) from chest X-ray images. Chaos Solitons Fractals 2020, 140, 110245. [CrossRef]

118. Actualmed COVID-19 Chest X-ray Dataset. 2020. Available online: https://github.com/agchung/Actualmed-COVID-chestxraydataset (accessed on 12 July 2020).

119. Maguolo, G.; Nanni, L. A critic evaluation of methods for COVID-19 automatic detection from X-ray images. Inf. Fusion 2021, 76, 1-7. [CrossRef] 
120. Chung, A. COVID Chest X-ray Dataset. 2020. Available online: https://github.com/agchung/Figure1-COVID-chestxray-dataset (accessed on 3 June 2020).

121. SARS-CoV-2 CT-Scan Datase. June 2020. Available online: https:/ /www.kaggle.com/plameneduardo/sarscov2-ctscan-dataset (accessed on 17 December 2021).

122. COVID-19 X-ray Dataset (Train \& Test Sets) with COVID-19CNN. April 2020. Available online: https://www.kaggle.com/ khoongweihao/covid19-xray-dataset-train-test-sets (accessed on 17 December 2021).

123. Armato, S.G.; Drukker, K.; Li, F.; Hadjiiski, L.; Tourassi, G.D.; Engelmann, R.M.; Giger, M.L.; Redmond, G.; Farahani, K.; Kirby, J.S.; et al. LUNGx Challenge for computerized lung nodule classification. J. Med. Imaging 2016, 3, 044506. [CrossRef]

124. COVID-19 Detection X-ray Dataset. Available online: https://kaggle.com/darshan1504/covid19-detection-xray-dataset (accessed on 17 December 2021).

125. Vayá, M.d.l.I.; Saborit, J.M.; Montell, J.A.; Pertusa, A.; Bustos, A.; Cazorla, M.; Galant, J.; Barber, X.; Orozco-Beltrán, D.; Garcia, F.; et al. BIMCV COVID-19+: A large annotated dataset of RX and CT images from COVID-19 patients. arXiv 2020, arXiv:2006.01174.

126. Wang, X.; Peng, Y.; Lu, L.; Lu, Z.; Bagheri, M.; Summers, R.M. Chestx-ray8: Hospital-scale chest x-ray database and benchmarks on weakly-supervised classification and localization of common thorax diseases. In Proceedings of the IEEE Conference on Computer Vision and Pattern Recognition. 2017. Available online: https:/ / openaccess.thecvf.com/content_cvpr_2017/html/ Wang_ChestX-ray8_Hospital-Scale_Chest_CVPR_2017_paper.html (accessed on 17 December 2021).

127. COVID-19 X-ray Images. Available online: https://www.kaggle.com/bachrr/covid-chest-xray (accessed on 17 December 2021).

128. Setio, A.A.A.; Traverso, A.; de Bel, T.; Berens, M.S.; Bogaard, C.V.D.; Cerello, P.; Chen, H.; Dou, Q.; Fantacci, M.E.; Geurts, B.; et al. Validation, comparison, and combination of algorithms for automatic detection of pulmonary nodules in computed tomography images: The LUNA16 challenge. Med. Image Anal. 2017, 42, 1-13. [CrossRef] [PubMed]

129. Jaeger, S.; Candemir, S.; Antani, S.; Wáng, Y.-X.J.; Lu, P.-X.; Thoma, G. Two public chest X-ray datasets for computer-aided screening of pulmonary diseases. Quant. Imaging Med. Surg. 2014, 4, 475-477.

130. Cohen, J.P.; Morrison, P.; Dao, L.; Roth, K.; Duong, T.Q.; Ghassemi, M. COVID-19 image data collection: Prospective predictions are the future. arXiv 2020, arXiv:2006.11988.

131. Islam, M.; Karray, F.; Alhajj, R.; Zeng, J. A Review on Deep Learning Techniques for the Diagnosis of Novel Coronavirus (COVID-19). IEEE Access 2021, 9, 30551-30572. [CrossRef] [PubMed]

132. Hemanjali, A.; Revathy, S.; Anu, V.M.; MaryGladence, L.; Jeyanthi, P.; Ritika, C.G. Document Clustering on COVID literature using Machine Learning. In Proceedings of the 2021 5th International Conference on Computing Methodologies and Communication (ICCMC), Erode, India, 8-10 April 2021.

133. Shorten, C.; Khoshgoftaar, T.M. A survey on image data augmentation for deep learning. J. Big Data 2019, 6, 1-48. [CrossRef] 